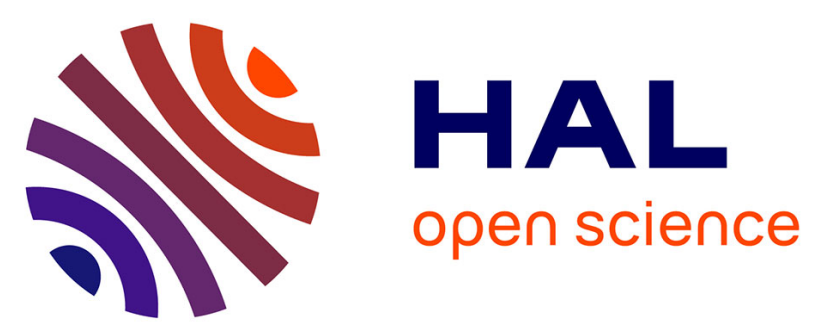

\title{
Environmental Plasmonic Spectroscopy of Silver-Iron Nanoparticles: Chemical Ordering under Oxidizing and Reducing Conditions
}

Julien Ramade, Emmanuel Cottancin, Marie-Ange Lebeault, Cyril Langlois, Laurent Piccolo, Michel Broyer, Matthias Hillenkamp, Jean Lerme, Florent Calvo, Michel Pellarin

\section{To cite this version:}

Julien Ramade, Emmanuel Cottancin, Marie-Ange Lebeault, Cyril Langlois, Laurent Piccolo, et al.. Environmental Plasmonic Spectroscopy of Silver-Iron Nanoparticles: Chemical Ordering under Oxidizing and Reducing Conditions. Journal of Physical Chemistry C, 2019, 123 (25), pp.15693-15706. 10.1021/acs.jpcc.9b02422 . hal-02361740

\author{
HAL Id: hal-02361740 \\ https://hal.science/hal-02361740
}

Submitted on 1 Oct 2020

HAL is a multi-disciplinary open access archive for the deposit and dissemination of scientific research documents, whether they are published or not. The documents may come from teaching and research institutions in France or abroad, or from public or private research centers.
L'archive ouverte pluridisciplinaire HAL, est destinée au dépôt et à la diffusion de documents scientifiques de niveau recherche, publiés ou non, émanant des établissements d'enseignement et de recherche français ou étrangers, des laboratoires publics ou privés. 


\section{Environmental Plasmonic Spectroscopy of Silver-}

\section{Iron Nanoparticles: Chemical Ordering Under}

\section{Oxidizing and Reducing Conditions}

Julien RAMADE, ${ }^{1}$ Emmanuel COTTANCIN, ${ }^{1, *}$ Marie-Ange LEBEAULT, ${ }^{1}$ Cyril LANGLOIS, ${ }^{2}$

Laurent PICCOLO, ${ }^{3}$ Michel BROYER, ${ }^{1}$ Matthias HILLENKAMP, ${ }^{1}$ Jean LERMÉ, ${ }^{1}$ Florent

CALVO $^{4}$ and Michel PELLARIN ${ }^{1}$

${ }^{1}$ Univ. Lyon, Université Claude Bernard Lyon 1, CNRS, Institut Lumière Matière, UMR 5306, F- 69622 Villeurbanne, France

${ }^{2}$ Univ. Lyon, INSA-Lyon, MATEIS, Université Claude Bernard Lyon 1, UMR 5510 CNRS, 69621 Villeurbanne Cedex France

${ }^{3}$ Univ. Lyon, Université Claude Bernard - Lyon 1, IRCELYON - UMR 5256, 2 avenue Albert Einstein, 69626 Villeurbanne Cedex, France

${ }^{4}$ University Grenoble Alpes and CNRS, LIPHY, F-38000 Grenoble, France

AUTHOR INFORMATION

Corresponding Author: *emmanuel.cottancin@univ-lyon1.fr 
Abstract: The chemical structure and the localized surface plasmon resonance (LSPR) of sizeselected $\mathrm{Ag}_{\mathrm{x}} \mathrm{Fe}_{1-\mathrm{x}}(\mathrm{x}=0.5,0.8)$ nanoparticles $(\mathrm{NPs})$, produced by laser vaporization, were investigated experimentally and theoretically. Monte Carlo simulations employing a many-bodyembedded-atom model show that small isolated Ag-Fe NPs should preferentially adopt core@shell structures with an iron core that may be deformed or off-centered while keeping a silver shell around it. Experimentally, the optical response of silica-embedded NPs was measured with a new environmental spectrophotometer based on spatial modulation and is discussed in relation with the NP chemical structure independently studied by transmission electron microscopy (TEM). Measurements performed on as-prepared samples show that iron rapidly oxidizes when exposed to air to form a magnetite $\left(\mathrm{Fe}_{3} \mathrm{O}_{4}\right)$ shell surrounding a purely metallic crystalline silver core. In situ optical measurements carried out successively under oxidizing and reducing atmospheres indicate that iron oxidation and reduction are reversible processes that are directly mirrored in the LSPR changes, in good agreement with optical simulations. The TEM observations, the environmental plasmonic spectroscopy measurements and the various simulations lead us to conclude that iron and silver initially adopt a segregated configuration with a silver-enriched surface and that, during oxidation, iron likely diffuses throughout the silver shell, leading to an $\mathrm{Ag} @ \mathrm{Fe}_{3} \mathrm{O}_{4}$ configuration, while an inverse process may occur during annealing under reducing atmosphere. Finally, we show that $\mathrm{Ag}$-Fe NPs, co-deposited with alumina on a substrate kept at $400^{\circ} \mathrm{C}$, offers an alternative to preserve the metallic character of iron. 


\section{Introduction}

Multicomponent nanoparticles (NPs) may adopt various structures (alloys, Janus, core-shell...) $)^{1-4}$ and their optical properties have generated unceasing experimental and theoretical investigations over the last decades. ${ }^{5-8}$ Among all possible materials, coinage metal-based nanoalloys are of great interest as they display a strong resonance in the near UV-visible range (the so-called localized surface plasmon resonance or LSPR), the features of which depend not only on the morphology (size, shape) and environment of the NPs, but also on their internal structure that itself depends on these parameters. One primary interest of studying their optical properties lies in shaping their LSPR by tuning the relative proportion of constituents and their chemical ordering. In addition, optical spectroscopy is a nondestructive method for probing the chemical structure of the NPs and their possible chemical modifications such as oxidation or reduction for instance, both in individual NPs ${ }^{9}$ and in NP assemblies. ${ }^{10-11}$

Moreover, the LSPR of the NP can be used as a local probe of the modifications of its immediate environment, as for example the adsorption of molecules at its surface. ${ }^{12}$ In this respect, plasmonic sensing provides a promising tool to monitor the real-time kinetics of reactions occurring at the vicinity of the NPs, ${ }^{13-15}$ or directly within the NPs, when one component evolves under a reactive environment. ${ }^{10}$ Novel or enhanced properties can also arise owing to the LSPR and its related enhanced local field around the NP. For this purpose, a plasmonic metal is ideally combined with another material presenting a different functionality (catalytic, chemically active, magnetic, optical...). Such combinations with efficient optical absorption ${ }^{16}$ should result in the development of new nanocomposite materials denoted as active or passive hybrid NPs with promising applications. For active hybrid NPs, the functionality of the second material involves an interaction 
with the LSPR that can be magneto-plasmonic, ${ }^{17-18}$ photocatalytic, ${ }^{19}$ or lead to enhanced fluorescence. ${ }^{20}$ For passive hybrid systems, which is the topic of the present work, the second material acts as the environment of the plasmonic counterpart, ${ }^{8}$ and changes in its chemical or physical structure can efficiently be probed through the induced LSPR changes. ${ }^{21}$ This method is useful in various fields such as heterogeneous catalysis, gas sensing ${ }^{22}$ or biosensing. ${ }^{23-24}$ A reactive environment may induce structural modifications of the NPs that strongly affect their properties, and, in turn, their optical response. The real-time monitoring of their evolution can be directly observed at the single NP level owing to environmental transmission electron microscopy (ETEM) imaging. ${ }^{25-29}$ However such observations have to be combined with global environmental characterizations at the scale of larger NP assemblies in order to determine whether the processes observed on single NPs are representative for the whole sample. The ongoing development of in situ and real-time optical spectroscopy combined with ETEM techniques is essential for a better understanding of the mechanisms involved during chemical and physical rearrangements. Recently we reported ETEM observations ${ }^{30}$ and ex-situ optical spectroscopy ${ }^{10}$ on indium-silver nanoalloys. The reduction of the core-shell In- $\mathrm{Ag} @ \operatorname{In}_{2} \mathrm{O}_{3}$ was observed by ETEM and oxidation/reduction cycles were demonstrated through LSPR shifts. Here, we present a new setup allowing in-situ optical measurements of a NP assembly, complementary to single NP ETEM observations. The set-up is tested on iron-silver NPs, which combine a plasmonic material with a ferromagnetic transition metal, thus providing an interesting system in the field of active hybrid NPs. ${ }^{31}$ Moreover, iron is a potential candidate for low-cost catalysis applications, ${ }^{32-33}$ even though it is also very vulnerable to oxidation. Unfortunately, the Ag-Fe system at the nanoscale is not easy to stabilize. Iron (or iron oxide)-noble metal hybrid NPs have been the subject of many investigations, ${ }^{34-42}$ and some studies focused on silver-iron ${ }^{43-45}$ or silver-iron oxide with promising 
applications in the field of antimicrobial treatment and water decontamination. ${ }^{46-50}$ It should be stressed here that both metals are immiscible in the bulk at all compositions ${ }^{51}$ Moreover, at the nanoscale, the NPs at thermodynamic equilibrium conditions should have a surface enriched in silver because of the difference in surface energies between the two metals, namely $1.86 \mathrm{~J} \cdot \mathrm{m}^{-2}$ and $0.925 \mathrm{~J} \cdot \mathrm{m}^{-2}$ for $\mathrm{Fe}$ and $\mathrm{Ag}$, respectively. ${ }^{52}$ Experimentally, depending on the synthesis method various configurations may be obtained including Janus ${ }^{44}$ and sometimes metastable structures ${ }^{45}$ In chemical syntheses the kinetics and the nature of the surfactants strongly affects the final structure and reverse core@shell Ag@Fe NPs may also be obtained. ${ }^{53}$

A different, physical route was used here for the synthesis of $\mathrm{Ag}_{\mathrm{x}} \mathrm{Fe}_{1-\mathrm{x}}$ nanoparticles, as reported in a previous study ${ }^{11}$ at the specific composition $\mathrm{x}=0.5$. The NPs were generated in the gas phase by laser vaporization of bimetallic targets and then deposited onto adequate substrates. We have shown that, although simple thermodynamic considerations suggest core-shell structures with an iron core and a silver shell in the ground state, we always observe Janus-like segregated structures, termed "nano-fried-eggs". ${ }^{11}$ The silver part of the NP forms a pure metallic nanosphere, whereas the iron part is shown to rapidly react with the environment to form amorphous oxides or carbides. Despite the high reactivity with the environment and a probable structural rearrangement, the particles retain both plasmonic and ferromagnetic properties. ${ }^{11}$

Beyond this first characterization essentially focused on the structural and magnetic properties of the deposited or embedded $\mathrm{Fe}_{0.5} \mathrm{Ag}_{0.5}$ NPs, we conduct here a detailed study for two silver compositions ( $50 \%$ and $80 \%$ ), by investigating the chemical properties of the NPs through TEM and environmental optical spectroscopy, and interpreting the combined physico-chemical observations with the help of Monte Carlo (MC) simulations of their structural stability at finite temperature. 
In the present study, NPs of two relative compositions $\left(\mathrm{Ag}_{0.8} \mathrm{Fe}_{0.2}\right.$ and $\left.\mathrm{Ag}_{0.5} \mathrm{Fe}_{0.5}\right)$ were codeposited in a silica matrix for optical measurements in a controlled environment. In this respect, a new setup, based on the spatial modulation spectroscopy (SMS) technique, so far used for single NP spectroscopy, ${ }^{54-55}$ and allowing the measurement of the optical absorption of embedded clusters in a reactive gaseous environment at various temperatures, was developed. The setup was used to probe the chemical ordering of iron-silver NPs under reducing or oxidizing conditions. TEM and optical characterizations were performed just after air exposure, showing that the system is segregated with a silver core surrounded by an oxidized iron shell. As will be shown below, the combination of TEM observations, environmental plasmonic measurements, optical and atomistic Monte Carlo simulations provides insight into the native structure of the NPs and its evolution during the redox cycles.

The manuscript is organized as follows. In the next section we present the modeling through Monte Carlo simulations providing information about the expected chemical ordering of the native system. After a description of the new experimental setup in section 3, TEM and optical characterizations of the NPs after air exposure are presented followed by their optical response under controlled environment. The optical responses of obtained structures implemented in optical simulations are compared to the optical spectra measured just after air exposure or after annealing under reducing atmosphere. Based on these results we propose a scenario of the evolution of the chemical ordering under reducing and oxidizing atmospheres.

\section{Atomistic Modeling of Ag-Fe nanoalloys}

Iron-silver nanoalloys are relatively poorly documented, and we have begun their investigation with some computational modeling under the ideal conditions of isolated systems. The purpose of 
this section is to explore the structure and finite temperature behavior of medium size nanoparticles containing approximately 1000 atoms, for compositions considered in experiments, namely $80 \%$ and $50 \%$ in silver. For such relatively large sizes, methods using an explicit description of electronic structure are not practical and we rely on semiempirical many-body potentials together with advanced Monte Carlo methods to sample the potential energy surface efficiently at finite temperature. As a first step towards understanding the fundamental behavior of Ag-Fe nanoalloys, our modeling refers to isolated nanoparticles without any contact with a substrate or a matrix.

\subsection{Methods}

The embedded-atom potential by Zhou and coworkers ${ }^{56}$ was employed to model the nanoparticles, and parallel tempering MC simulations were undertaken to explore low-energy structures and phase changes in the temperature range extending over the melting region. The initial configurations of the nanoparticles were designed with a body-centered-cubic (BCC) iron core of cubic shape and truncated edges, on which six truncated silver pyramids with height parallel to the (001) crystallographic direction were placed following the $\mathrm{Ag}(001) / \mathrm{Fe}(001)$ epitaxial relationship at $45^{\circ}$. Under such symmetry constraints, the number of atoms for both metals is not arbitrary, and the desired compositions are satisfied within a few percents.

The simulations were initially carried out using 32 temperatures distributed geometrically in the 200-1500 K range, allowing for occasional exchanges between random pairs of configurations from neighboring trajectories every $10 \mathrm{MC}$ cycles (one cycle being equivalent to $\mathrm{N}$ individual moves where $\mathrm{N}$ is the total number of atoms). After some first simulations, the analysis of the success rates of exchange moves allows adjusting the temperature ladder, removing some of the low temperature replicas and adding others at intermediate temperatures, where thermal 
fluctuations are stronger. At the $80 \%$ composition in silver, the simulations were found to converge much faster by also choosing a lowest temperature of $300 \mathrm{~K}$ instead of $200 \mathrm{~K}$, as taken at the $50 \%$ composition.

Inherent structures (IS) were located by systematically optimizing the configurations visited onthe-fly along the course of the MC trajectories. If a structure with lower energy than the existing pool was found, the Monte Carlo simulations were entirely restarted from this putative global minimum and a further quench analysis repeated after it, up to 3 of these iterations being necessary until no better candidate was found.

The final simulations consisted of $10^{7}$ Monte Carlo cycles per trajectory, with averages accumulated after $5 \times 10^{6}$ cycles. In addition to standard thermodynamical quantities such as the internal energy $U=\langle E\rangle$ and its temperature derivative or heat capacity $C_{v}(T)=\partial U / \partial T$, variations in the degree of chemical ordering were quantified using the mixing order parameter $\mu$ already used to characterize nanoalloys. ${ }^{57}$ This parameter is defined for each configuration $\mathbf{R}$ from the local connectivity of individual atoms as

$\mu(\mathbf{R})=\frac{N_{F e F e}+N_{A g A g}-N_{F e A g}}{N_{F e F e}+N_{A g A g}+N_{F e A g}}$

$N_{A B}$ denoting the number of A-B bonds between nearest neighbors. The parameter $\mu$ displays high positive values for phase segregated systems but much lower and, depending on composition, possibly negative values for alloyed structures. Here all bonds within $3.5 \AA$ were considered when calculating $\mu$.

The inherent structures extracted by local optimization from the individual MC trajectories were also used for analyzing the results, as they capture the structural information but are free of thermal noise. They were sorted according to their energies $\left\{E_{\alpha}\right\}$ at each temperature, and from the 
corresponding distributions the root mean square fluctuation $\chi$ was calculated. The spreading of IS distributions is reflected in the value of $\chi$, an hypothetical crystalline state being such that $\chi=$ 0 while a fluid state would exhibit large values of $\chi$. This quantity is also complementary to the conventional heat capacity because it does not include the kinetic contribution to the thermal fluctuations, all vibrations being frozen in inherent structures.

\subsection{Thermodynamical equilibrium}

To shed more light onto the physics of Ag-Fe nanoalloys, computational modeling of small nanoparticles containing approximately 1000 atoms and initially taken as symmetric core-shell structures were undertaken in the temperature range $200-1500 \mathrm{~K}$. The main thermodynamical properties are the internal energy and the heat capacity whose variations with temperature are shown in Figure 1a and Figure 1b for the 50\% and 80\% silver compositions, respectively.

The extent of chemical ordering, as characterized by the mixing order parameter $\mu$ in Eq. (1), is shown as well in Figure 1c. The thermodynamical results are best analyzed by also looking at representative samples of the structures visited at different temperatures and labelled as i-iii and $I$ III in Figure 1c and shown in Figure 2.

The high values of the mixing parameter $\mu$ at low temperature are indicative of phase separation and are consistent with the initialization of simulations on core-shell structures. However, the parallel tempering Monte Carlo simulations were occasionally able to locate structures significantly lower in energy than the perfectly symmetric octahedral minima. In particular, for the $50 \%$ composition two types of nearly isoenergetic shapes consisting of centered (i) and offcentered (Janus-like type, ii) core-shell nanoalloys are found. At $80 \%$ silver composition, a more significant deviation from the initial structure occurs with the iron core adopting a very prolate, cigar-like structure and several isolated iron atoms dissolved in the larger silver shell (I). 


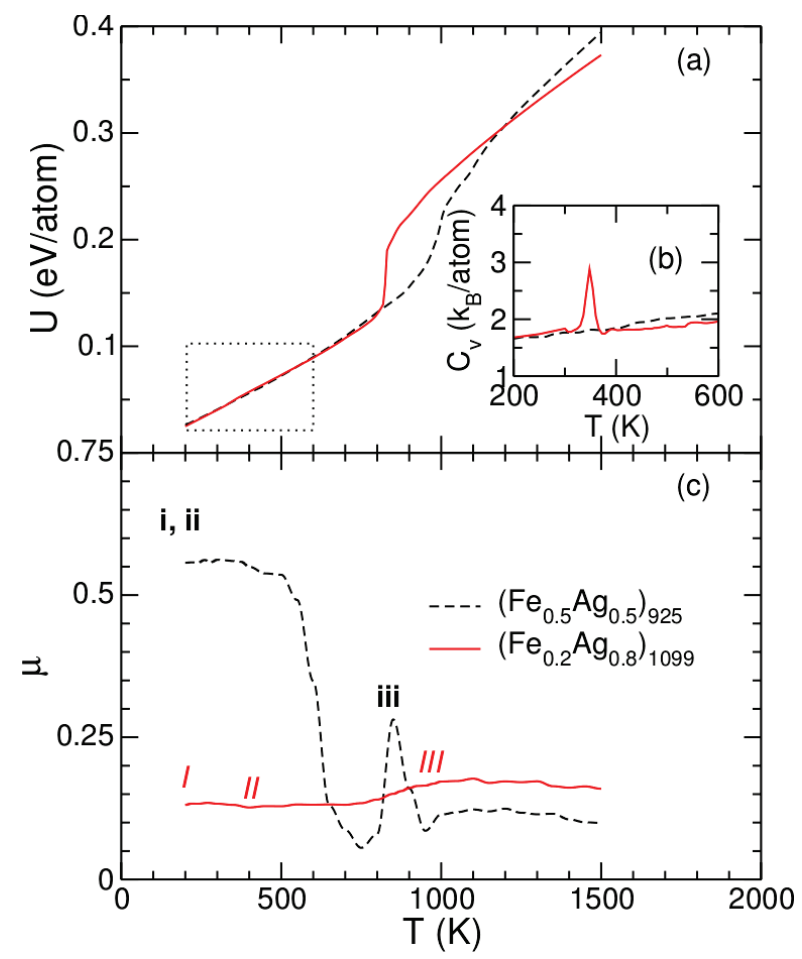

Figure 1. Predicted thermodynamical properties of Ag-Fe nanoalloys containing about 1000 atoms at silver compositions of $80 \%$ and $50 \%$, as obtained from parallel tempering Monte Carlo simulations and as a function of canonical temperature. (a) Internal energy; Inset (b) Heat capacity in the 200-600 K range highlighted by the dotted rectangle in (a); (c) Mixing index $\mu$, as defined in Eq.(1). In panel (c) the numbers i-iii and I-III refer to typical structures depicted in Figure 2.

From the pure thermodynamical perspective, the internal energies exhibit smoothly increasing variations with temperature with marked jumps at 850 or $1000 \mathrm{~K}$ depending on composition. These large jumps are the manifestation of melting, which, as discussed further below, can be directly visualized on the nanoparticles themselves. However, this major phase change has no direct signature on the mixing order parameter, which shows complementary information about the extent of chemical ordering within the nanoparticles. At $50 \%$ silver composition, $\mu$ exhibits a strong drop near $600 \mathrm{~K}$, followed by a minimum at $750 \mathrm{~K}$ and a subsequent peak at $850 \mathrm{~K}$. These 
features will be best interpreted from the inherent structures. At $80 \%$ silver composition the mixing parameter mildly decreases at low temperature, reaching also a minimum near $400 \mathrm{~K}$, and smoothly increases across the melting range above $800 \mathrm{~K}$.

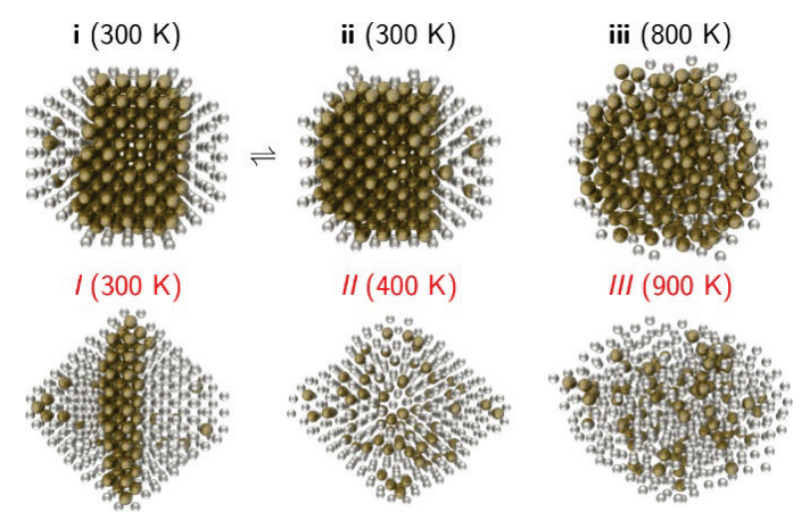

Figure 2. Half-cut structures of Ag-Fe nanoalloys at various temperatures, as borrowed from the Monte Carlo simulations and corresponding to the labels i-iii at 50\% silver composition and I-III at $80 \%$ silver composition in Figure 1.

Inherent structures provide a more systematic connection between the finite temperature results and the underlying atomistic arrangements. The spectra of inherent structures obtained by systematic quenching along the Monte Carlo trajectories are represented in Figure 3 for the two systems. On the same line as the internal energy, the IS spectra show one main increase of about $0.1 \mathrm{eV} /$ atom at the respective melting temperatures of the two systems. However, even down to room temperature the spectra have a finite broadening and show that the equilibrium phase is composed of various minima that differ more in chemical ordering rather than in global structure. The fluctuations $\chi$ in the IS energies, depicted as insets in Figure 3 for the two systems, emphasize the thermal signatures of structural changes that were not so clear in the heat capacity. There are notably two minor peaks at $750 \mathrm{~K}$ and $350 \mathrm{~K}$ on this quantity for the $50 \%$ and $80 \%$ silver compositions, respectively, that match the temperatures at which the mixing index reaches a minimum in Figure 1c. 
Typical structures sampled in the range between these temperatures and the melting points are shown in Figure 2 as labels iii and II. At 50\% silver composition, the structure depicted illustrates the amorphization transition that occurs without much latent heat and could thus be considered as a second-order like phase change. At $80 \%$ silver composition and at $400 \mathrm{~K}$, the iron core appears essentially dissolved in the lattice structure imposed by the larger silver shell. Melting in this NP is sharper than at the $50 \%$ composition and, consistently with the lower melting point of silver as compared to that of iron, occurs earlier as well. The liquid phase is associated with multiple amorphous inherent structures showing iron atoms dissolved below the outermost silver layer, a feature also shared by the nanoparticle with $50 \%$ silver. An example of inherent structure of the liquid like state of the $80 \%$ silver NP at $900 \mathrm{~K}$ can be seen in Figure 2(III).

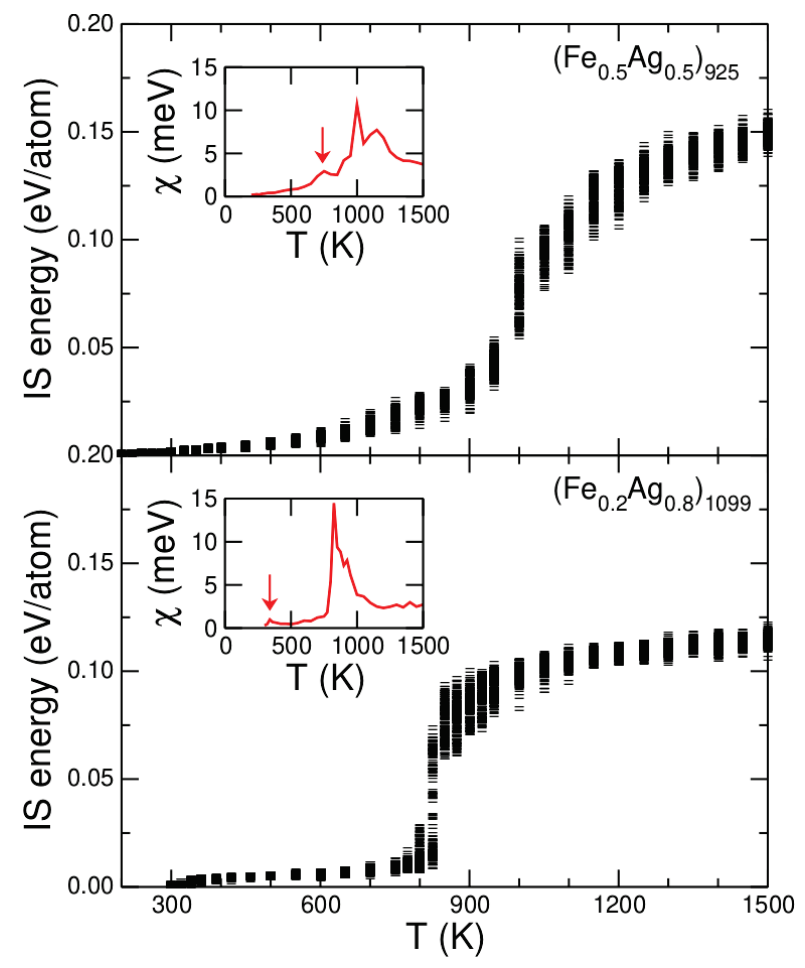


Figure 3. Spectra of inherent structure energies $\left\{E_{\alpha}\right\}$ of Ag-Fe nanoalloys obtained by systematic quenching of the instantaneous configurations visited along the Monte Carlo simulations. The insets show the root mean square fluctuations of these energy distributions. Upper panel: $50 \%$ silver composition; Lower panel: $80 \%$ silver composition.

Under room temperature conditions, our modeling thus predicts that isolated Ag-Fe nanoparticles preferentially adopt core-shell crystal structures. However, the iron core may not necessarily be as symmetric as the outer shell and could adopt either an off-centered position keeping a silver monolayer around it (case of the 50\% composition, structure ii) or even undergo strong deformations to accommodate a significantly elongated core (case of the $80 \%$ composition, structure I). In section 4 we explore the consequences of such morphologies on the optical response for larger nanoparticles of experimental relevance and attempt to connect these predictions to measurements.

\section{Experimental methods}

\subsection{Cluster Synthesis}

Thin dielectric films containing bimetallic clusters with low volume concentrations have been synthesized according to the low-energy cluster beam deposition technique (LECBD) described in previous papers. ${ }^{58}$ The clusters are initially produced in the gas phase by a laser vaporization source. The second harmonic of a nanosecond $\mathrm{Nd}^{3+}$ :YAG pulsed laser is focused on the surface of the target of desired composition that is confined in a small chamber with an aperture at the level of the nozzle in the presence of a continuous flow of helium gas (a few tens of mbar). The atomic plasma thus generated is rapidly cooled down by collisions with the inert gas, leading to nucleation and growth of small bimetallic clusters having between $2 \mathrm{~nm}$ and $6 \mathrm{~nm}$ in diameter. The 
particle/gas mixture then expands through the nozzle in the form of a supersonic beam into a high vacuum chamber. As laser vaporization is known to favor the growth of nanoalloys with the same average composition as the target one,${ }^{59}$ bimetallic $\mathrm{Ag}_{\mathrm{x}} \mathrm{Fe}_{(1-\mathrm{x})}$ particles were produced from target rods with $\mathrm{x}=50 \%$ or $80 \%$ in atomic compositions. The $\mathrm{x}$ value given in the following corresponds to an average with some fluctuations for the produced NPs.

The charged clusters can be size-selected before deposition with a quadrupole static deviator acting as an energy selector of the ionized clusters (of about $5 \%$ of the produced clusters). Because of the almost constant velocity of the clusters, the deviator serves as a mass filter. ${ }^{60}$ The average cluster size is directly measured with a Wiley-McLaren time-of-flight (TOF) mass spectrometer located downstream of the deviator. The clusters are finally either deposited on a TEM grid (ultrathin carbon on holey carbon films supported on a copper grid) or co-deposited on a fused silica substrate $(1 \mathrm{~cm} \times 1 \mathrm{~cm}, 1 \mathrm{~mm}$ thick) simultaneously with a transparent amorphous silica matrix $(200 \mathrm{~nm}-$ $300 \mathrm{~nm}$ thickness) evaporated by an electron gun. The low volume fraction of cluster matter in the thin dielectric films (a few \%) prevents from significant coalescence and optical coupling between the nanoparticles. With an appropriate shadow mask, the resulting samples are composed of two adjacent areas, a first region with matrix-embedded clusters and a second region with only the matrix which serves as the reference. It should be stressed that the evaporation speed may have an influence on the porosity of the matrix, which can slightly modify its average optical refractive index.

3.2 In situ optical spectroscopy using Spatial Modulation Spectroscopy (SMS)

\subsubsection{Principle of SMS for nanocomposite samples}


In this part we briefly present a new setup that allows the measurement of the absorption of matrix-embedded clusters deposited on a transparent substrate with a low optical density and in an environment with controlled atmosphere and temperature. More precisely, we determine the absorption coefficient $\alpha(\lambda)$ of a nanocomposite film of thickness $d$ as in a conventional spectrophotometer. However, for very low optical densities, the sensitivity has to be improved. For this purpose, we developed a new setup built on the principle of spatial modulation spectroscopy ${ }^{55}$ that will also be suited for environmental spectroscopy experiments on single larger NPs. In SMS a light beam from a white lamp is focused on the sample surface on which NPs are dispersed in low concentration and spatially oscillates at frequency $f$. Due to its absorption and scattering, a nano-object exposed to the oscillating light beam induces a modulation of the transmitted light power. The transmitted signal (denoted $D C$ ) can be demodulated with a lock-in amplifier (either at $f$ or $2 f$ ) to generate a second signal denoted $X_{f, 2 f}$ that, once normalized as $\frac{X_{f, 2 f}}{D C}$, leads to the absolute extinction cross-section of the object, provided the beam spot profile is fully characterized. ${ }^{55}$ Similar experiments can be performed with matrix-embedded cluster samples by modulating the beam spot position between a region with clusters and a region without clusters in the matrix (see Figure 4a). The sample is composed of an absorbing zone with absorption coefficient $\alpha(\lambda)$ between $x \rightarrow-\infty$ and $x=0$ and a transparent region between $x=0$ and $x \rightarrow+\infty$ along the $\mathrm{x}$ axis. $P_{o}(\lambda)$ being the incident power and $I_{o}(\lambda, x, y)$ the intensity distribution of the spot on the sample plane, the relative transmitted power writes

$$
\frac{\Delta P}{P_{o}}=\frac{P_{t r}(\lambda)-P_{o}(\lambda)}{P_{o}(\lambda)}=\int_{-\infty}^{0} d x \int_{-\infty}^{+\infty} d y I_{N}(\lambda, x, y) e^{-\alpha(\lambda) d}+\int_{0}^{+\infty} d x \int_{-\infty}^{+\infty} d y I_{N}(\lambda, x, y)-1
$$

which can be simplified as 


$$
\frac{\Delta P}{P_{o}}=-\left(1-e^{-\alpha(\lambda) d}\right) \int_{-\infty}^{0} d x \int_{-\infty}^{+\infty} d y I_{N}(\lambda, x, y) \text { where } I_{N}(\lambda, x, y)=\frac{I_{o}(\lambda, x, y)}{P_{o}(\lambda)} \text { is the normalized }
$$

intensity distribution $\left(\iint I_{N}(\lambda, x, y) d x d y=1\right)$ of the spot (see also Figure $4 \mathrm{~b}$ ). If the spot position $x_{s}(t)$ oscillates at the frequency $f$ like $x_{s}(t)=x_{o}+\delta_{x} \cos (2 \pi f t)$ it can be shown that: $\frac{\Delta P(t)}{P_{o}}=$ $-\left(1-e^{-\alpha(\lambda) d}\right) U\left(x_{s}(t)\right)$ with $U\left(x_{s}(t)=\int_{-\infty}^{-x_{S}(t)} d X \int_{-\infty}^{+\infty} d y I_{N}(\lambda, X, y)\right.$ and $X=x-x_{s}(t)$. $U\left(x_{s}(t)\right)$ can be decomposed in Fourier series as follows

$$
U_{s}\left(\lambda, x_{s}(t)\right)=\frac{A_{o}}{2}+A_{1} \cos (2 \pi f t)+B_{2} \sin (4 \pi f t)+\cdots
$$

The Fourier coefficients $A_{o}, A_{1}, B_{2}$ of $U\left(x_{s}(t)\right)$ can be obtained if the spot profile is well characterized (see Supporting Information for details) and the transmitted signal, once demodulated with a lock-in amplifier, allows $\frac{X_{f}}{D C}$, and thus the absorption coefficient $\alpha(\lambda)$ related to the absorption cross-section of the NPs to be accessed through

$$
\alpha(\lambda)=-\frac{1}{d} \ln \left(1-\frac{\frac{X_{f}}{D C}}{\frac{X_{f A_{O}}}{D C}+\frac{A_{1}}{\sqrt{2}}}\right)
$$

\subsubsection{SMS setup dedicated to environmental measurements}

An overview of the SMS setup is displayed in Figure 4c. The sample is set inside a chamber under a controlled gaseous atmosphere and fixed on a heating sample holder (HSH) that can reach up to $250^{\circ} \mathrm{C}$. This sample-HSH system is connected to motorized linear stages outside the reactor, allowing a 3-axes-displacement with a spatial resolution of about $0.5 \mu m$ (see Figure S1). A turbomolecular pump and a gas injection system are directly connected to the reactor, allowing optical measurements under high vacuum $\left(10^{-7} \mathrm{mbar}\right)$ or small pressures of reactive gases (up to a static pressure of a few hundreds mbar inside the reactor). 

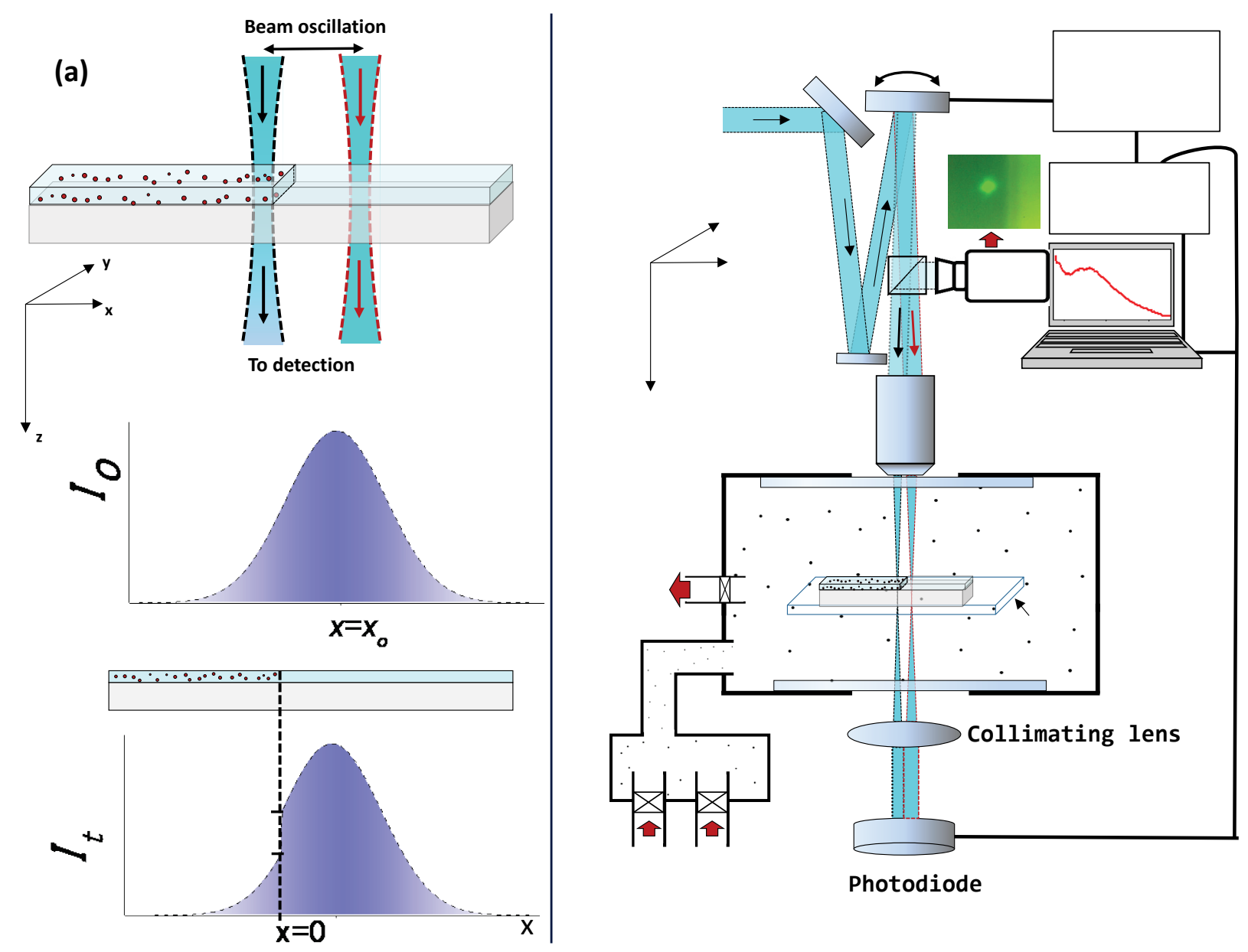

Figure 4. (a) Principle of spatial modulation spectroscopy. A monochromatic collimated beam is focused at the diffraction limit at the frontier between the two areas of the sample (with and without NPs). The spatial modulation of the spot on either side of the border induces a modulation of the transmitted light. (b) View of the intensity distribution of the spot upstream and downstream the sample; the NPs absorption in the sample involves a lowering of the intensity for $\mathrm{x}<0$ highlighted by the two short horizontal lines. (c) Schematic overview of the setup adapted for environmental measurements. The splitter cube is used to image the sample (image in green above the camera with the incident light spot and the vertical border between both regions with and without clusters in the matrix). 
The light provided by a white source (ENERGETIC, model EQ-99) is first sent into a monochromator (Shamrock 193i, ANDOR); the monochromatic output light beam is then focused onto a circular pinhole of diameter $\phi=180 \mu \mathrm{m}$ acting as a source point. The monochromatic beam is then collimated and redirected by a set of aluminum mirrors onto an oscillating mirror (THORLABS) controlled by a low-frequency generator. The beam subsequently oscillates with a few mrad, before being focused on the sample surface by an achromatic reflective microscope objective (Cassegrain type Edmunds, 15X/0.28NA, WD=23.75 mm) located outside the reactor and allowing a UV-near IR working spectral band (300-1000 nm). The beam oscillation induces a spatial modulation of a few $\mu m$ on the sample. The transmitted light is collected by a lens before being detected by a photodiode and sent to the lock-in amplifier, which takes its sine reference from the low-frequency generator controlling the oscillating mirror. The quartz window at the entrance of the reactor induces some spectral dispersion, especially in the blue-UV range. Consequently, the spot profile on the sample (maintained at a given $z$ position) strongly evolves with the wavelength in the UV range and requires to be fully characterized so as to obtain the Fourier coefficients $A_{o}, A_{1}, B_{2}$ and thus the absorption coefficient $\alpha$ over the whole spectral range of interest. For that purpose, a razor blade stuck on a glass substrate corresponding to a total absorbing medium $(\alpha(\lambda) \rightarrow \infty)$ was used. Profile lines were then recorded for various wavelengths around the border with small oscillation amplitudes of the spot. This provided the Fourier coefficients and thus allowed a calibration curve using Eq. (2) to be obtained (see Figure S2, S3 and S4).

\subsection{Transmission Electron Microscopy}


TEM experiments were performed with a FEI TITAN Transmission Electron Microscope (TEM) $\mathrm{G} 2$ operating at $300 \mathrm{kV}$ and corrected for spherical aberrations of the objective lens $\left(\mathrm{C}_{\mathrm{s}}\right.$ corrector). The oxidized or metallic state of the observed crystalline phases can be clearly discriminated by measuring the interplanar spacing. High-resolution images can be obtained in the HAADF-STEM mode because the size of the nanoprobe can be reduced down to $0.1 \mathrm{~nm}$ even if the microscope is not probe corrected. For these experiments, NPs were deposited on supported ultrathin amorphous carbon films (ultrathin carbon on Holey Carbon films, AGAR inc.) or $\mathrm{Si}_{3} \mathrm{~N}_{4}$ thin films and in some cases sandwiched between two silica layers ( $5 \mathrm{~nm}$ thickness) evaporated with the electron gun.

\section{Results and discussion}

\subsection{TEM characterization of the NPs after air exposure: spontaneous oxidation of iron}

First TEM observations of NPs with 50\% silver with a fairly large size distribution, in various environments and after air-exposure have already been reported. ${ }^{11}$ For uncapped NPs or NPs embedded in silica it was shown that iron and silver segregate with a quasi-spherical silver part surrounded by an amorphous iron oxide structure. The similar structure for uncapped NPs and silica-embedded NPs suggests that the contact of the NPs with the matrix has a minor influence on their morphology.

We here show results on mass-selected NPs with two different silver compositions. TEM characterizations were first performed after air exposure on size-selected NPs with $50 \%$ of silver $(\langle\phi\rangle=4.5 \pm 0.3 \mathrm{~nm}$ deduced from mass spectrometry or $N \approx 3340$ atoms $)$ deposited on a layer of silica $(2 \mathrm{~nm})$ with a very low concentration to avoid any coalescence $\left(\approx 250 \mathrm{NPs} / \mu \mathrm{m}^{2}\right.$, equivalent bulk thickness of $0.01 \mathrm{~nm}$ ). The low magnification image displayed in Figure 5a shows NPs with two clearly distinguishable segregated phases. The almost spherical darker parts of the 
NPs, corresponding to silver, were size analyzed over a population of a few hundreds NPs. The corresponding size distribution (Figure 5b) follows a log-normal distribution centered at $3.6 \mathrm{~nm}$.

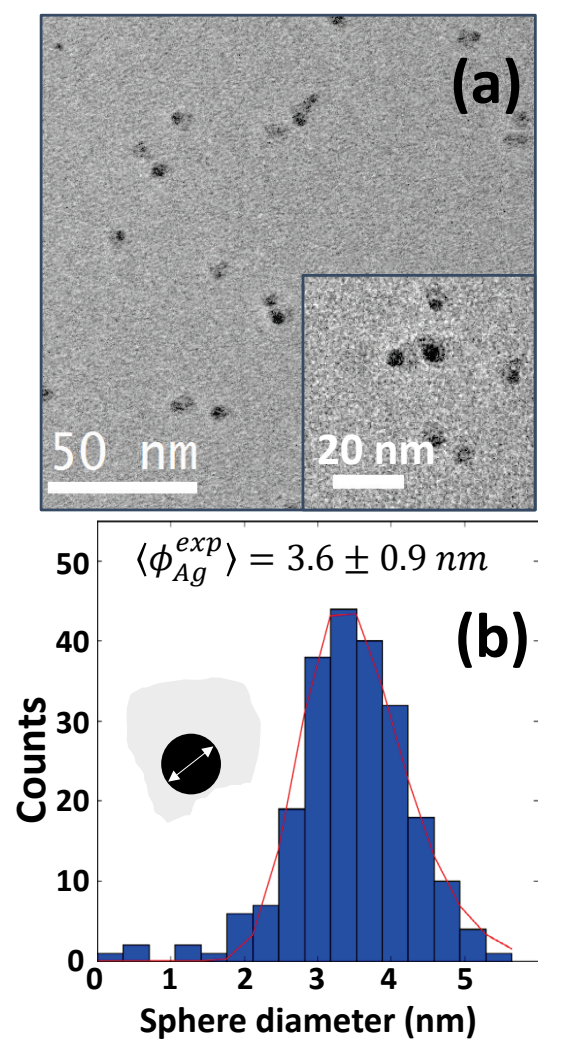

Figure 5. (a) TEM image of Ag-Fe NPs with $50 \%$ of silver deposited on a $2 \mathrm{~nm}$ silica layer itself deposited on $\mathrm{Si}_{3} \mathrm{~N}_{4}$ thin films after air exposure. (b) Size distribution of the silver dark parts of the NPs deduced from the analysis of the dark areas $(S)$ and assuming a spherical geometry $\emptyset=$ $2 \sqrt{S / \pi}$

Assuming that silver and iron completely segregate and that silver form spheres, the expected diameter of the silver part was obtained from the total diameter $\langle\emptyset\rangle$ of the NPs deduced from the Wiley-McLaren TOF through $\left\langle\emptyset_{A g}\right\rangle=\sqrt[3]{\langle\emptyset\rangle^{3}-4 N r_{s-F e}^{3}}$ where $r_{s-F e}=0.141 \mathrm{~nm}$ is the WignerSeitz radius of iron. We obtain $\left\langle\emptyset_{A g}\right\rangle \approx 3.8 \mathrm{~nm}$, which is in rather good agreement with TEM image analysis leading to $\left\langle\emptyset_{A g}^{e x p}\right\rangle=3.6 \pm 0.9 \mathrm{~nm}$. The broader size distribution of silver clusters 
reflects the fluctuations of $\mathrm{x}$, the silver composition of mixed clusters. The iron oxide part should display the surface of a $5.7 \mathrm{~nm}$ diameter sphere as predicted from the spherical assumption assuming a face-centered cubic (FCC) lattice parameter of $\mathrm{Fe}_{3} \mathrm{O}_{4}$ of $0.839 \mathrm{~nm}$. However, its surface analysis could not be achieved since the external boundaries are hardly distinguishable. Yet, the large visible surfaces suggest that iron oxide wets the surface of thin films (silica or carbon) more efficiently than the silver cluster surface, ${ }^{11}$ although TEM tomography should be performed to ascertain this conclusion. The analysis of this sample, in which coalescence was avoided, shows that only one silver sphere exists in each NP, which further indicates that the segregation between silver and iron probably occurs before iron oxidation, in agreement with the MC simulations discussed in section 2.

HAADF-STEM and HRTEM observations were also performed for $50 \%$ and $80 \%$ silver compositions, either on uncapped NPs or on NPs sandwiched between two silica layers $(2 \mathrm{~nm}$ below and $5 \mathrm{~nm}$ above). It should be emphasized that the silica evaporated with the electron gun is known to be porous. ${ }^{10}$ For both concentrations the HAADF-STEM images of Figure $6 \mathrm{a}$ and $6 \mathrm{c}$ clearly show two regions with different contrast in each NP due to differences in atomic number $Z$. The brighter almost spherical regions correspond to silver $(\mathrm{Z}=47)$ whereas the less defined darker ones correspond to iron $(\mathrm{Z}=26)$. For the $50 \%$ silver composition, an energy dispersive $\mathrm{x}-$ ray mapping performed on a single NP confirms this hypothesis (inset in Figure 6a). 


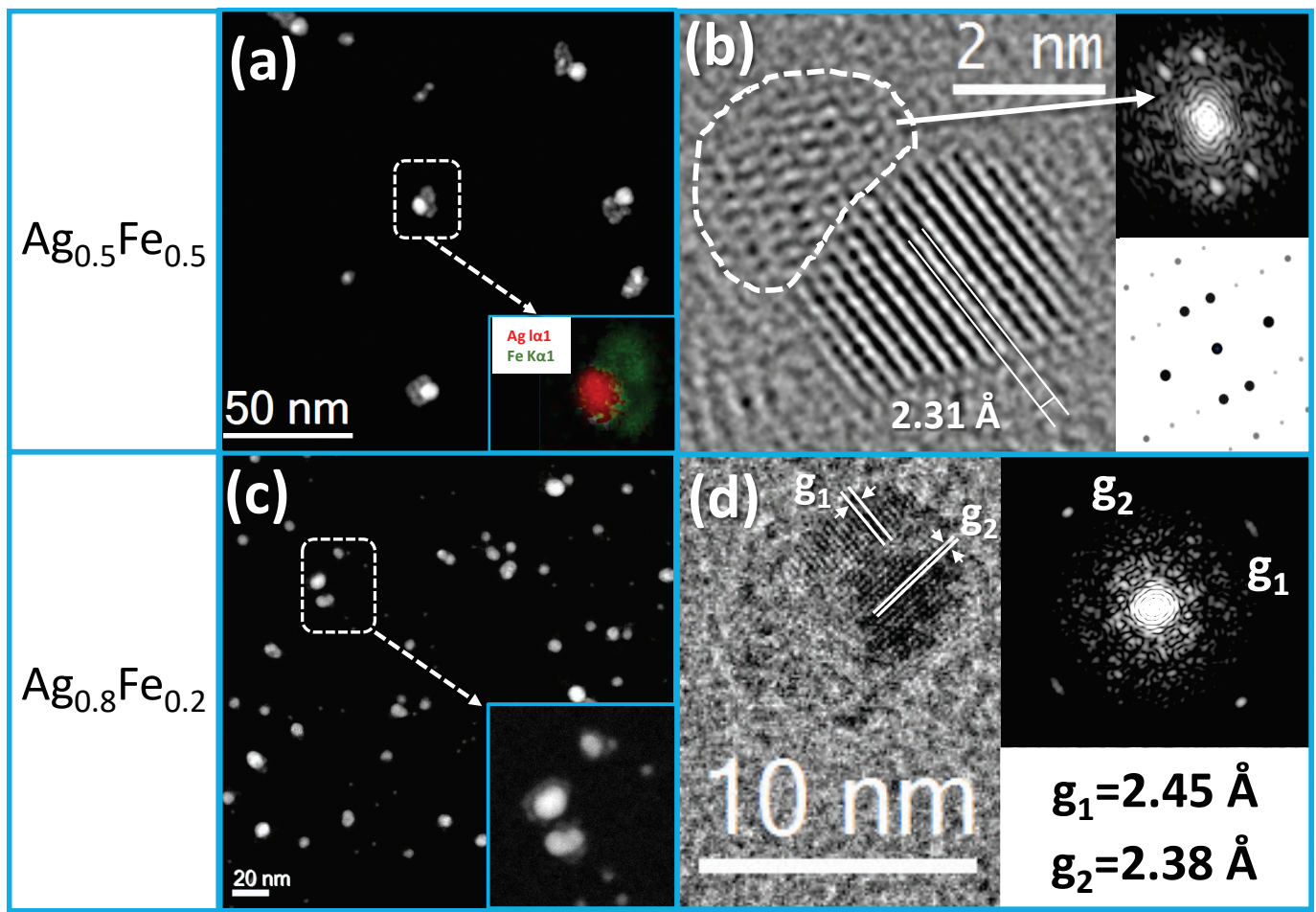

Figure 6. TEM images after air-exposure of $\mathrm{Ag}_{0.5} \mathrm{Fe}_{0.5}$ NPs between two silica layers (upper panels) and of $\mathrm{Ag}_{0.8} \mathrm{Fe}_{0.2}$ NPs deposited on amorphous carbon (lower panels). (a) and (c) HAADFSTEM images. Inset of (a) energy dispersive x-ray mapping of a single NP with $50 \%$ silver composition for which the spectral lines correspond to the $\mathrm{L}_{\alpha 1}$ transition at $3 \mathrm{keV}$ for silver and the $\mathrm{K}_{\alpha 1}$ line at $6.4 \mathrm{keV}$ for iron. (b) HRTEM images and fast Fourier transform (FFT) of the areas of low density (upper right corner) compared to the simulated FFT of magnetite $\mathrm{Fe}_{3} \mathrm{O}_{4}$ (or maghemite $\gamma-\mathrm{Fe}_{2} \mathrm{O}_{3}$ ) oriented along the axis [130] (right lower corner). The interplanar spacing of the fully crystalline structure $(2.31 \AA)$ is close to the $(111)$ plane of silver $\left(d_{111}(\mathrm{Ag})=2.35 \AA\right)$. (d) HRTEM image and its FFT image (upper right corner): the interplanar distances $g_{1}$ and $g_{2}$ may correspond to the (311) or (222) plane of magnetite $\mathrm{Fe}_{3} \mathrm{O}_{4}$ (or maghemite $\gamma-\mathrm{Fe}_{2} \mathrm{O}_{3}$ ) and to the (111) plane of silver, respectively. 
The observations for the $\mathrm{Ag}_{0.8} \mathrm{Fe}_{0.2}$ samples are in good agreement with previous observations for the $\mathrm{Ag}_{0.5} \mathrm{Fe}_{0.5}$ system, ${ }^{11}$ i.e. the silver part crystallizes in face-centered-cubic (FCC) or multiply twinned pure nanospheres, whereas the iron part forms amorphous structures that crystallize into magnetite $\left(\mathrm{Fe}_{3} \mathrm{O}_{4}\right)$ or maghemite $\left(\gamma-\mathrm{Fe}_{2} \mathrm{O}_{3}\right)$ under continuous electron beam irradiation (see Figure $6 \mathrm{~b}$ and $6 \mathrm{~d}$ ). These two iron oxides present the same FCC crystalline structure with almost identical lattice parameters $\left(0.833 \mathrm{~nm}\right.$ and $0.839 \mathrm{~nm}$ for maghemite ${ }^{61}$ and magnetite, ${ }^{62}$ respectively), making them undistinguishable from one another by HRTEM observations. However, the difference between their enthalpy of formation $\left(-811.6 \mathrm{~kJ} \mathrm{~mol}^{-1}\right.$ for maghemite and $-1120.9 \mathrm{~kJ} \cdot \mathrm{mol}^{-}$ ${ }^{1}$ for magnetite ${ }^{63}$ ) should favor magnetite. The discrimination between both structures is not essential for the present work, but it could be achieved by electron energy loss spectroscopy (EELS). ${ }^{64}$ It is only under continuous electron irradiation that iron oxide crystallizes, while remaining amorphous if not exposed to electron irradiation, as in the samples dedicated to optical measurements. Yet, the nearly systematic presence of iron oxide at the surface is consistent with the relatively low surface energies of magnetite or maghemite $\left[\sigma_{\mathrm{s}}\left(\mathrm{Fe}_{3} \mathrm{O}_{4}\right)=0.79 \mathrm{~J} \cdot \mathrm{m}^{-2}\right.$ and $\sigma_{\mathrm{s}}(\gamma-$ $\left.\left.\mathrm{Fe}_{2} \mathrm{O}_{3}\right)=0.57 \mathrm{~J} \cdot \mathrm{m}^{-2}\right]$, compared to the silver value $\left(0.925 \mathrm{~J} \cdot \mathrm{m}^{-2}\right)$. Also worthy of note is that silver oxide is absent. Due to its more noble character relative to iron, silver should be less reactive than transition metals such as iron. Moreover, iron oxide may protect silver from oxidation.

To conclude, the TEM observations and analyses of the NPs after air exposure show that a rapid oxidation of iron occurs at both silver compositions (50\% and $80 \%)$, even when the NPs are protected with silica, while silver remains metallic. The NPs form a compact crystallized silver core surrounded by a not-so-well defined iron oxide shell wetting the substrate. No hematite was observed and the iron oxide preferentially crystallizes into magnetite even if the presence of maghemite cannot be completely excluded. 


\subsection{Optical studies}

\subsubsection{Optical response of $\mathrm{Ag}_{\mathrm{x}} \mathrm{Fe}_{1-\mathrm{x}} \mathrm{NPs}$ in silica after air exposure}

The optical response of various elaborated samples of Ag-Fe NPs embedded in silica has been measured after air exposure and compared to theoretical predictions based on Mie theory and using the dipolar approximation. This last assumption is justified by the very small size of the NPs relative to the excitation wavelength, scattering being negligible with respect to absorption. In the absence of spherical symmetry, absorption cross-sections were calculated with the finite element method and using the COMSOL Multiphysics software. The dielectric functions of silver, iron and iron oxide were all taken from the literature. ${ }^{65-67}$
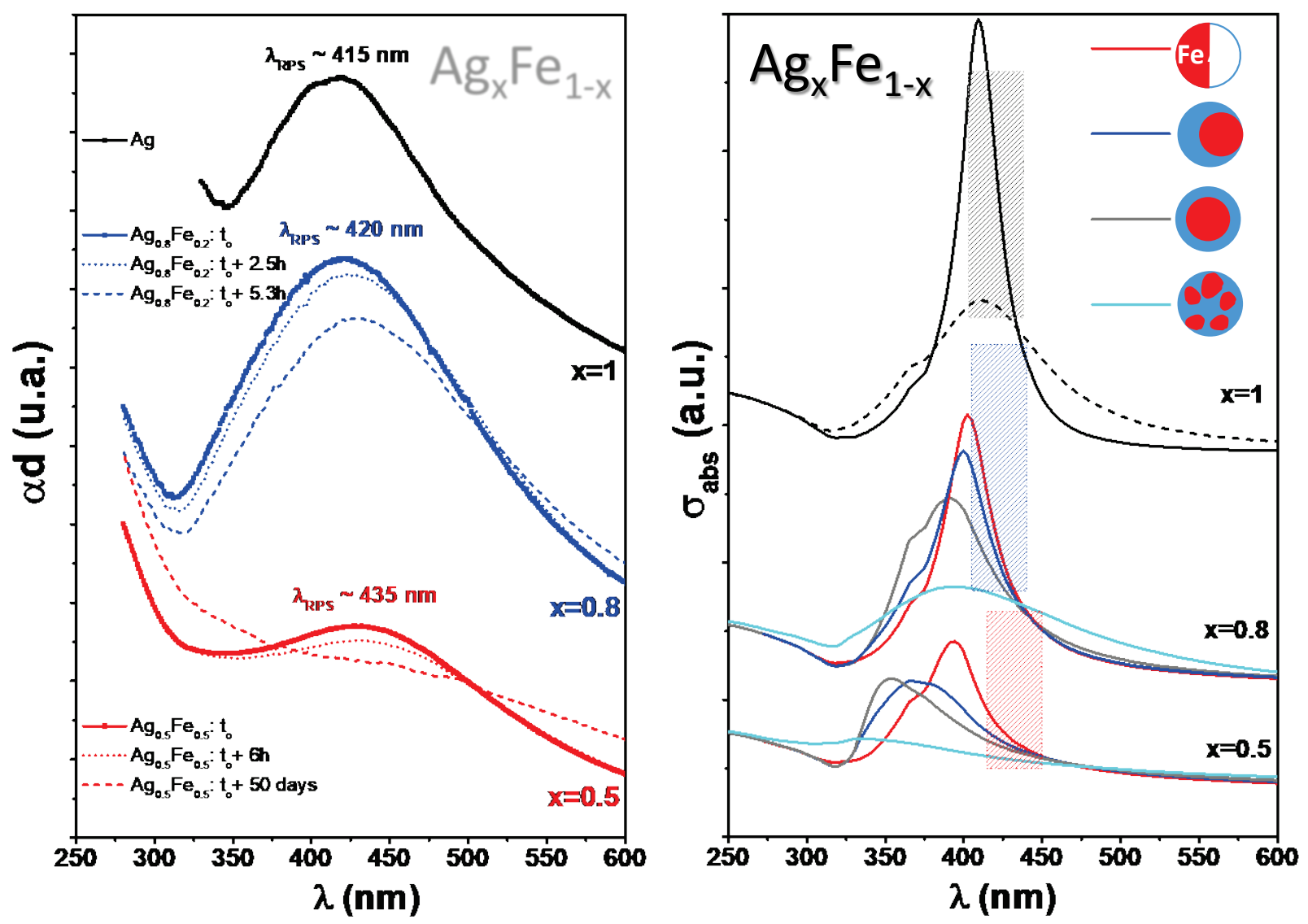
Figure 7. Optical absorption spectra of as-prepared $\mathrm{Ag}_{\mathrm{x}} \mathrm{Fe}_{1-\mathrm{x}} \mathrm{NPs}$ embedded in silica just after air exposure. (a) Experiments at $x=1$ (black), $x=0.8$ (blue), $x=0.5$ (red); the thin dotted line and dashed line curves correspond to the absorption spectra measured after ageing. (b) Theoretical predictions for various configurations: Janus (red line), off-centered spherical core-shell Fe@Ag (blue line), spherical core-shell Fe@Ag (gray line), spherical geometry assuming a stacking of silver and iron nano-domains for which the dielectric function is the weighted volumic average of both silver and iron dielectric functions (cyan line) and pure silver (black line). In this last case, the absorption cross-section of a silver sphere of $4 \mathrm{~nm}$ in diameter was also calculated by taking into account the decreasing of the electron mean free path in the NP (black dotted line). ${ }^{68}$ The hatched rectangular areas corresponding to the experimental positions of the resonances displayed in (a) highlight the opposing trends of the experimental and theoretical LSPR shifts with varying silver composition.

Samples of size-selected $\mathrm{Ag}_{\mathrm{x}} \mathrm{Fe}_{1-\mathrm{x}}$ clusters embedded in silica were elaborated for optical measurements. The obtained samples have an averaged diameter of $\left\langle\emptyset_{A g}\right\rangle=4.0 \pm 0.3 \mathrm{~nm}$, $\left\langle\emptyset_{A g_{0.8} F e_{0.2}}\right\rangle=4.6 \pm 0.3 \mathrm{~nm}$ and $\left\langle\emptyset_{A g_{0.5} F e_{0.5}}\right\rangle=4.0 \pm 0.3 \mathrm{~nm}$ for $\mathrm{x}=1,0.8$ and 0.5 , respectively. The corresponding absorption spectra are displayed in Figure $7 \mathrm{a}$ and compared to theoretical predictions for various geometrical configurations in Figure 7b. The LSPR of silver is well marked at around $415 \mathrm{~nm}$ and remains stable over a few days, whereas the LSPR of mixed NPs is damped, broadened and red-shifted with increasing iron proportion, which is at variance with our calculations. For pure silver NPs, the absorption cross-section of a silver sphere of $4 \mathrm{~nm}$ in diameter was also calculated by taking into account the decreasing of the electron mean free path in the NP (black dotted line). ${ }^{68}$ This effect induces a broadening and a damping of the LSPR that are both in better agreement with the experimental spectrum and with the size effects experimentally observed 
in this size range ${ }^{69}$ For mixed $\mathrm{Ag}_{\mathrm{x}} \mathrm{Fe}_{1-\mathrm{x}} \mathrm{NPs}$, the decrease of the electron mean free path should also induce a similar effect on the LSPR regardless of the configuration, but this effect is not straightforward to implement except for the spherical core@shell configuration through the use of the Granqvist formula. ${ }^{70}$ Both calculations have been performed only for the spherical core@shell configuration (see Figure S5 in supporting information). A damping of about a factor 2 without any shift of the LSPR is observed when the shortening of the mean free path is taken into account. Therefore, despite our theoretical spectra being less realistic due to the neglect of such phenomenological size effects, both calculations would lead to the same conclusions. Below, only calculations for Fe-Ag NPs without taking into account the decreasing of the electron mean free path are thus presented.

The LSPR of the mixed $\mathrm{Ag}_{\mathrm{x}} \mathrm{Fe}_{1-\mathrm{x}} \mathrm{NPs}$ is expected to be blue-shifted with increasing iron amount, for all Janus, centered and off-centered Fe@Ag spherical core-shell configurations. This is related to the increasing influence of iron which has a complex dielectric function. ${ }^{66}$ Assuming now that the effective dielectric function of the NPs is the weighted volumic average of both silver and iron dielectric functions, which is appropriate if $\mathrm{Ag}$ and $\mathrm{Fe}$ nanodomains are randomly distributed as pure nanodomains in the spherical NP, the LSPR is then expected to be strongly damped, especially for an amount of silver of $50 \%$, which is in contradiction with experimental spectra. Combined with TEM observations for which a single silver domain was always observed, this suggests that such an alloyed configuration is definitely unrealistic.

The difference in the behavior of the optical response with increasing iron composition between experiments and theory is most likely due to iron oxidation, as observed by TEM imaging. The progressive oxidation of a metal near a second plasmonic metal in bimetallic NPs leads to a redshift and damping of the LSPR induced by the complex dielectric function of the oxide part. ${ }^{59}$ As 
magnetite was shown to be the most likely oxide, the evolution of the optical response of $\mathrm{Ag}_{\mathrm{x}} \mathrm{Fe}_{1}$ ${ }_{x}$ NPs in silica computed for increasing levels of iron oxidation is reported in Figure 8, the dielectric function of magnetite $\mathrm{Fe}_{3} \mathrm{O}_{4}$ being extracted from Ref. ${ }^{67}$. Starting from Janus, centered or offcentered Fe@Ag spherical core-shell configurations, three scenarios of oxidation are proposed leading to centered or off-centered $\mathrm{Ag} @ \mathrm{Fe}_{3} \mathrm{O}_{4}$ spherical core-shell NPs, similarly to the structures observed by TEM. In the three cases, the LSPR is all the more red-shifted, broadened and damped that the initial composition is rich in iron and that the level of oxidation is high. Comparing with the experimental spectra obtained just after air exposure (see Figure 7a), we deduce that the NPs have an average oxidation level higher than $60 \%$ at both $50 \%$ and $80 \%$ silver compositions. After ageing the level of oxidation is even higher than $80 \%$ (see Figure 7a).

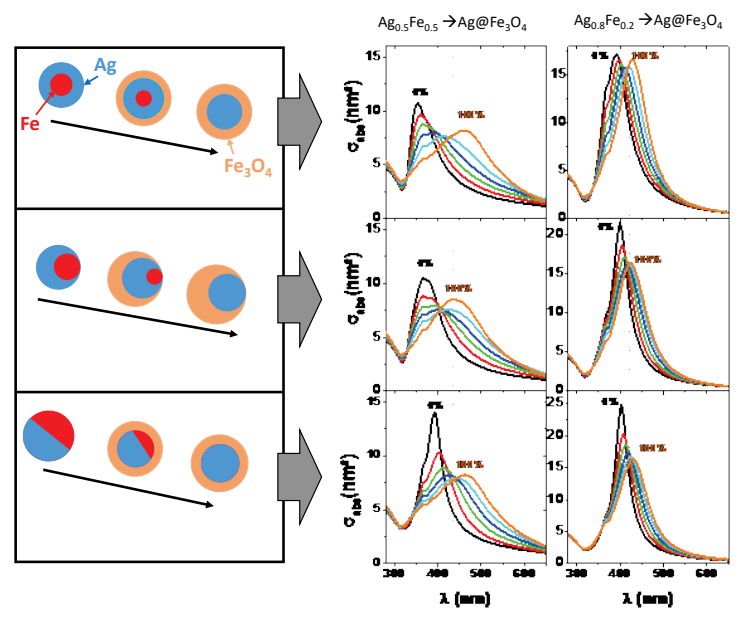

Figure 8. Evolution of the optical absorption cross-section of $\mathrm{Ag}_{\mathrm{x}} \mathrm{Fe}_{1-\mathrm{x}} \mathrm{NPs}(\mathrm{x}=0.5$ and $\mathrm{x}=0.8)$ embedded in silica with progressive iron oxidation for three scenarios in terms of red-shift, damping and broadening. (a) Scenario 1: from a centered spherical core-shell $\mathrm{Ag}_{\mathrm{x}} @ \mathrm{Fe}_{1-\mathrm{x}} \mathrm{NP}$ to a centered spherical core-shell $\mathrm{Ag} @ \mathrm{Fe}_{3} \mathrm{O}_{4} \mathrm{NP}$. (b) Scenario 2: from an off-centered spherical coreshell $\mathrm{Ag}_{\mathrm{x}} @ \mathrm{Fe}_{1-\mathrm{x}} \mathrm{NP}$ to an off-centered spherical core-shell $\mathrm{Ag} @ \mathrm{Fe}_{3} \mathrm{O}_{4}$ NP. (c) Scenario 3: from a Janus configuration $\mathrm{Ag}_{\mathrm{x}} / \mathrm{Fe}_{1-\mathrm{x}}$ to a centered spherical core-shell $\mathrm{Ag} @ \mathrm{Fe}_{3} \mathrm{O}_{4} \mathrm{NP}$. In all cases the 
iron oxidation level varies from $0 \%$ to $100 \%$ by steps of $20 \%$ for both compositions $\mathrm{x}=0.5$ and $\mathrm{x}=0.8$. The vertical gray dotted lines indicate the positions of the LSPR in the samples just after air exposure ( $435 \mathrm{~nm}$ and $420 \mathrm{~nm}$ for $\mathrm{x}=0.5$ and $\mathrm{x}=0.8$, respectively).

\subsubsection{Results after annealing}

The metallic character of iron may be recovered by annealing under reducing atmosphere. For this purpose, the samples were introduced in the home-built spectrophotometer described in section 3 after their initial air exposure at room temperature. Two identical cycles of reduction/oxidation were performed in the chamber with first some annealing at $250^{\circ} \mathrm{C}$ for 10 to 15 minutes under $\mathrm{H}_{2}(5 \%)-\mathrm{N}_{2}(95 \%)$ atmosphere and then a venting of the chamber to the atmosphere. Since the melting point of silica exceeds $1700{ }^{\circ} \mathrm{C}$, its structure should not be drastically modified during annealing, except a slight decrease of its porosity that would hardly change its optical index. The spectra recorded after each process are displayed in Figure 9 at both $80 \%$ and $50 \%$ silver compositions. The absorption spectra after annealing were recorded after returning at room temperature in the presence of hydrogen.

Even if the spectra are broad due to size, shape and porosity dispersion in the samples, some reproducible trends over both cycles can be noticed. First, the LSPR bands are broadened and damped after air exposure and better defined after annealing under hydrogen atmosphere. But the most apparent feature is the blueshift of the LSPR after annealing and the redshift after air exposure. This is clearer at $80 \%$ silver, as the LSPR maximum is better seen (see also Figure S6 and S7). The shifts after annealing or air exposure are larger for $\mathrm{Ag}_{0.8} \mathrm{Fe}_{0.2} \mathrm{NPs}$ because the amount of iron to be reduced or oxidized is smaller than for $\mathrm{Ag}_{0.5} \mathrm{Fe}_{0.5} \mathrm{NPs}$ for which the damping or the reappearing of the resonance are the strongest effects. The LSPR maximum for non-oxidized $\mathrm{Ag}_{0.5} \mathrm{Fe}_{0.5} \mathrm{NPs}$ is expected to be located below $400 \mathrm{~nm}$ whatever the configuration (see Figure 10), 
a threshold that is never crossed after annealing under $\mathrm{H}_{2}$ atmosphere. The reduction of iron therefore remains only partial after 10-15 minutes. Longer times or higher annealing temperatures are probably required to achieve complete reduction of the NPs.

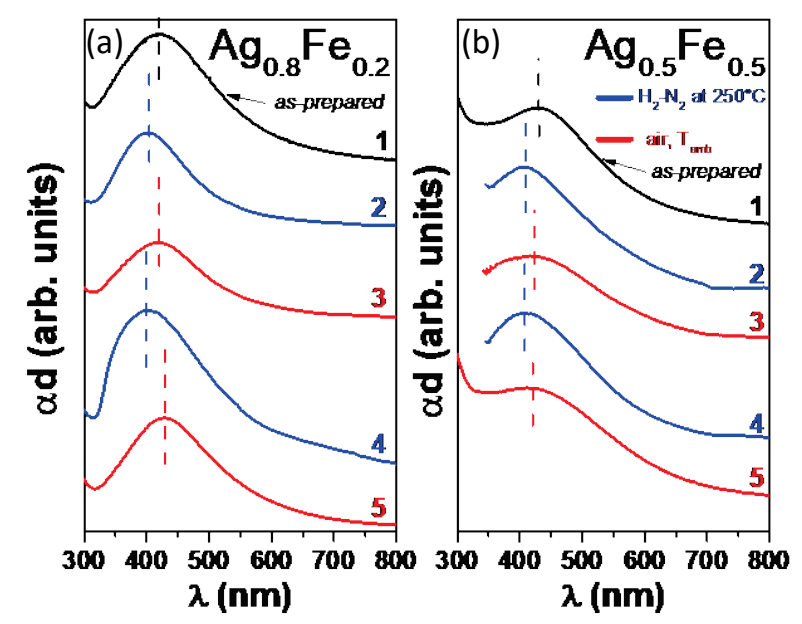

Figure 9. Cycles of in situ optical absorption measurements of $\mathrm{Ag}_{\mathrm{x}} \mathrm{Fe}_{1-\mathrm{x}} \mathrm{NPs}$ embedded in silica for (a) $\mathrm{x}=0.8$ and (b) $\mathrm{x}=0.5$, either after reducing under $\mathrm{H}_{2}-\mathrm{N}_{2}$ atmosphere at $250^{\circ} \mathrm{C}$ for $10-15$ minutes (blue curves) or after air exposure at room temperature (red curves). The black curves correspond to the spectra of the as-prepared samples recorded just after air exposure.

In the case of $\mathrm{Ag}_{0.8} \mathrm{Fe}_{0.2}$ NPs the LSPR peak position at around $400 \mathrm{~nm}$ is more compatible with a full reduction of iron oxide, except for the spherical core@shell configuration for which the LSPR maximum is expected near $390 \mathrm{~nm}$ (see Figure 10). However, this configuration is less likely, especially after annealing. 


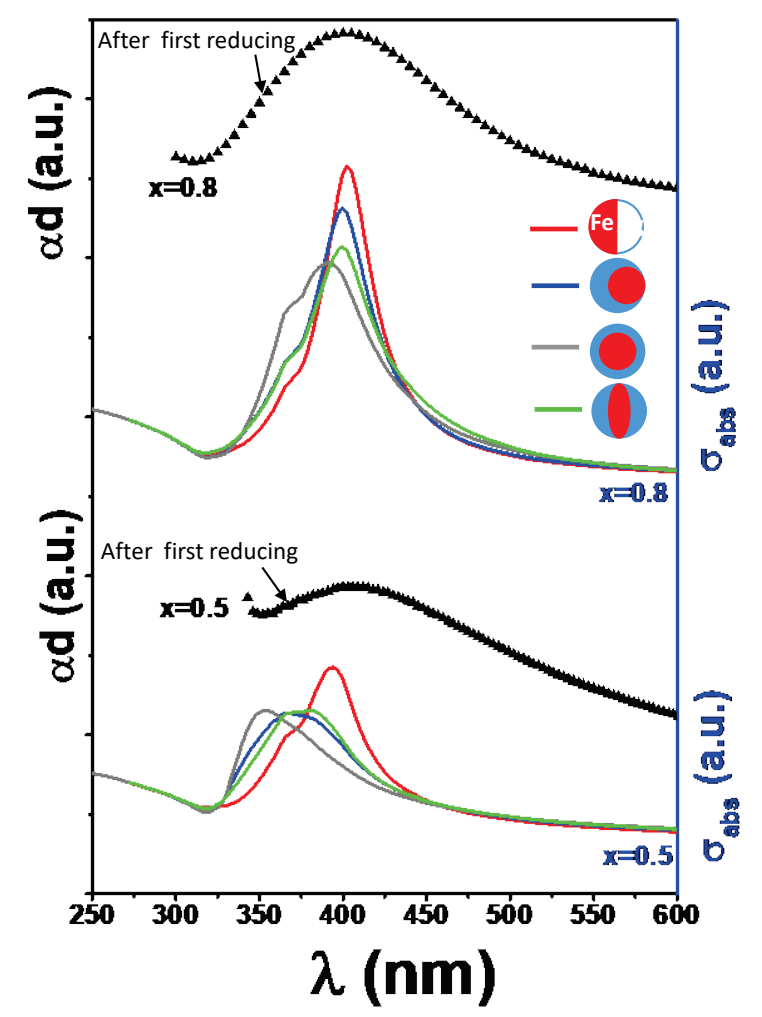

Figure 10. Absorption spectra of $\mathrm{Ag}_{\mathrm{x}} \mathrm{Fe}_{1-\mathrm{x}} \mathrm{NPs}$ embedded in silica (upper panel: $\mathrm{x}=0.8$, lower panel: $\mathrm{x}=0.5$ ). Experimental absorption spectra measured after reducing under $\mathrm{H}_{2}-\mathrm{N}_{2}$ atmosphere at $250^{\circ} \mathrm{C}$ corresponding to the spectra numbered 2 in Figure 9 (black triangles); theoretical absorption cross-sections for various configurations: Janus $\mathrm{Ag}_{\mathrm{x}} \mathrm{Fe}_{1-\mathrm{x}}$ (red curves); off-centered spherical core-shell Fe@Ag (blue curves), spherical core-shell Fe@Ag (gray curves), core-shell Fe@Ag with an oblate core similar to the predicted configurations from the Monte Carlo simulations (green curves).

In Figure 10, the absorption spectra for configurations similar to the ones deduced from atomistic Monte Carlo simulations are also shown, namely configurations obtained at $300 \mathrm{~K}$ for $50 \%$ and $80 \%$ silver compositions and labelled $\mathbf{i}$ and $I$ in Figure 2, respectively. They consist of an oblate iron core surrounded by a silver spherical shell. Their corresponding absorption spectra are very 
similar to the ones expected for an off-centered spherical core-shell Fe@Ag. This suggests that such configurations are also likely in our sample.

Nevertheless, definitive conclusions about the structure of the NPs, either just after elaboration or after reduction cannot be drawn easily only on the basis of optical spectroscopy that only allows segregated, alloyed or oxidized structures to be discriminated. To proceed further, complementary characterization techniques such as TEM or low energy ion spectroscopy ${ }^{71}$ should be performed on native NPs (before air exposure), which requires a vacuum transfer system that is currently missing. Nevertheless, no iron oxide was observed in Ag-Fe NPs deposited in ultra-high vacuum and capped with a thin layer of carbon on the order of $5 \mathrm{~nm}$ thick. ${ }^{11}$ We can thus conclude that the produced Fe-Ag NPs are not oxidized before venting.

Even without a complete characterization of the native structure, some conclusions may still be drawn on the possible evolution of the structure of the NPs during the cycles of oxidation and reduction, as sketched in Figure 11. The initial structure, expected from Monte Carlo simulations to be an Fe@Ag core-shell, should evolve to a segregated configuration with a more or less centered silver core surrounded by iron oxide, as observed through HRTEM and HAADF-STEM analyses and in agreement with the joint red-shift, broadening and damping of the LSPR. Annealing under reducing atmosphere induces a reduction reflected by the blue-shift and narrowing of the LSPR band. This reduction is surely not complete for the 50\% silver composition and the final configuration is probably more complex with three segregated phases where iron may be surrounded by silver and a remaining iron oxide domain. But other complex configurations can be envisioned at this stage. The air exposure inducing iron re-oxidation should then lead to the $\mathrm{Ag} @ \mathrm{Fe}_{\mathrm{x}} \mathrm{O}_{\mathrm{y}}$ core-shell configuration already observed after the first step of air exposure. The second redox cycle should lead to very similar configurations as the first cycle. 


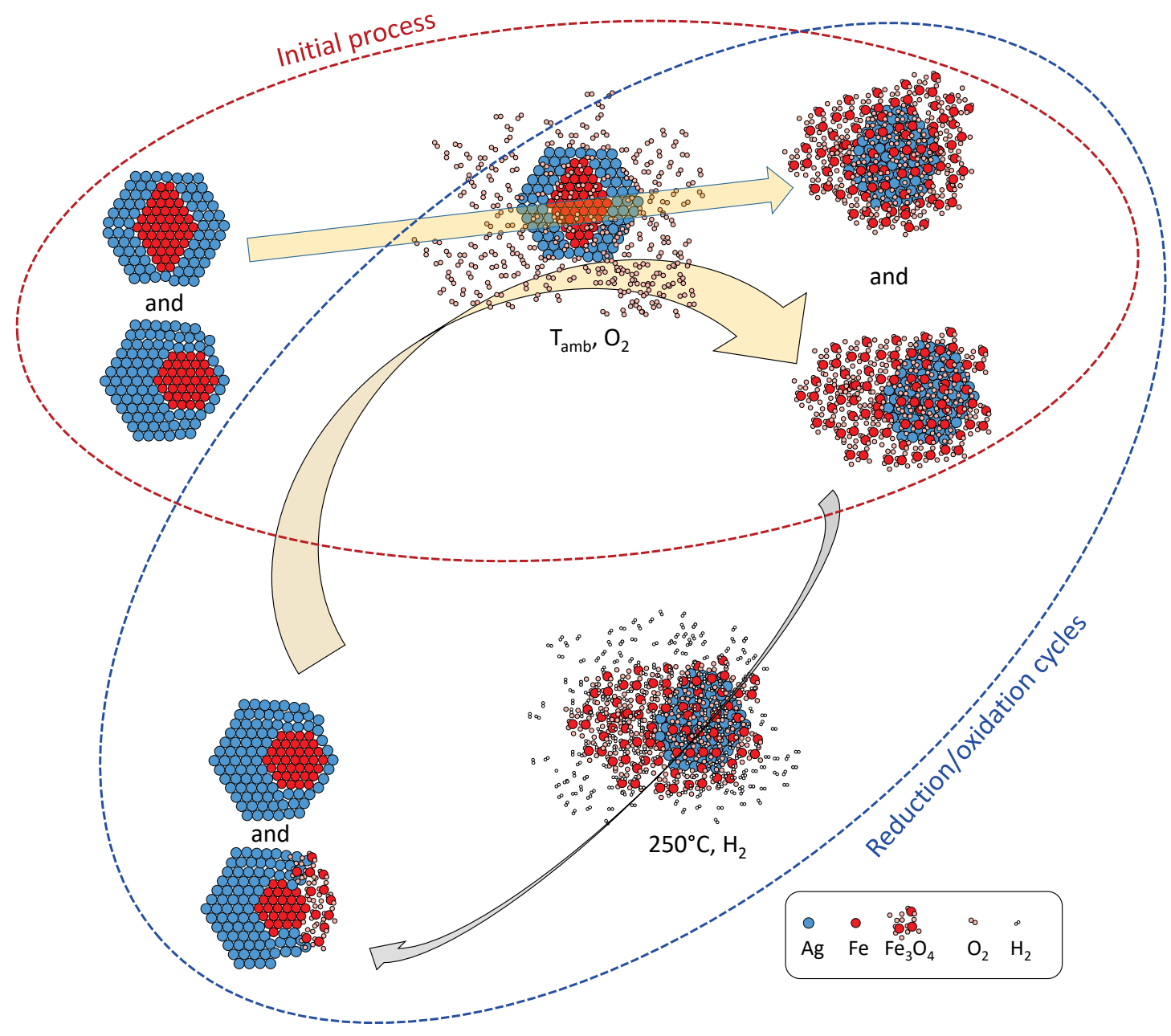

Figure 11. Plausible evolution of the Ag-Fe NP structure under oxidizing and reducing environments. The initial structure is assumed to be an Fe@Ag core-shell structure accordingly with atomistic MC simulations. After air exposure the NPs evolve to an $\mathrm{Ag} @ \mathrm{Fe}_{\mathrm{x}} \mathrm{O}_{\mathrm{y}}$ core-shell configurations and the annealing under reducing atmosphere leads to a more complex structure in which silver, iron and iron oxide are all present within the NP.

Finally, in order to minimize iron oxidation, $\mathrm{Ag}_{0.5} \mathrm{Fe}_{0.5}$ NPs were embedded in alumina (instead of silica) with the substrate kept at $400^{\circ} \mathrm{C}$ during co-deposition. This technique has previously been shown to be efficient to prevent copper NPs against oxidation. ${ }^{72}$ The optical absorption spectra of this sample can be seen in Figure 12. The optical index of alumina deposited at $400{ }^{\circ} \mathrm{C}$, varying 
from 1.71 to 1.64 in the UV-visible range, is higher than that of silica (1.47), hence the LSPR of metallic NPs embedded in alumina is expected to be red-shifted compared to metallic NPs embedded in silica. The first spectrum, recorded just after sample elaboration, displays an LSPR centered at $396 \mathrm{~nm}$ in good agreement with the calculated spectra for an off-centered spherical core@shell structure or a core@shell structure with an oblate core similar to the configuration obtained from Monte Carlo simulations. Moreover, no change is observed after one day. This strongly suggests that the NPs are preserved from oxidation during a longer time when elaborated under these conditions. The slight red-shift of the LSPR after almost two years shows that oxidation exists but is considerably slowed down. Metallic Ag-Fe NPs were nevertheless not observed by TEM because, as the thickness of alumina for TEM observations needs to be very low (a few nm), the NPs near the surface rapidly oxidize. However, embedding in alumina at $400^{\circ} \mathrm{C}$ is probably a good alternative for elaborating transparent matrix embedded Ag-Fe NPs while keeping their metallic character. To confirm this, XPS measurements on this type of samples as already performed on copper $\mathrm{NPs}^{72}$ will be needed. 


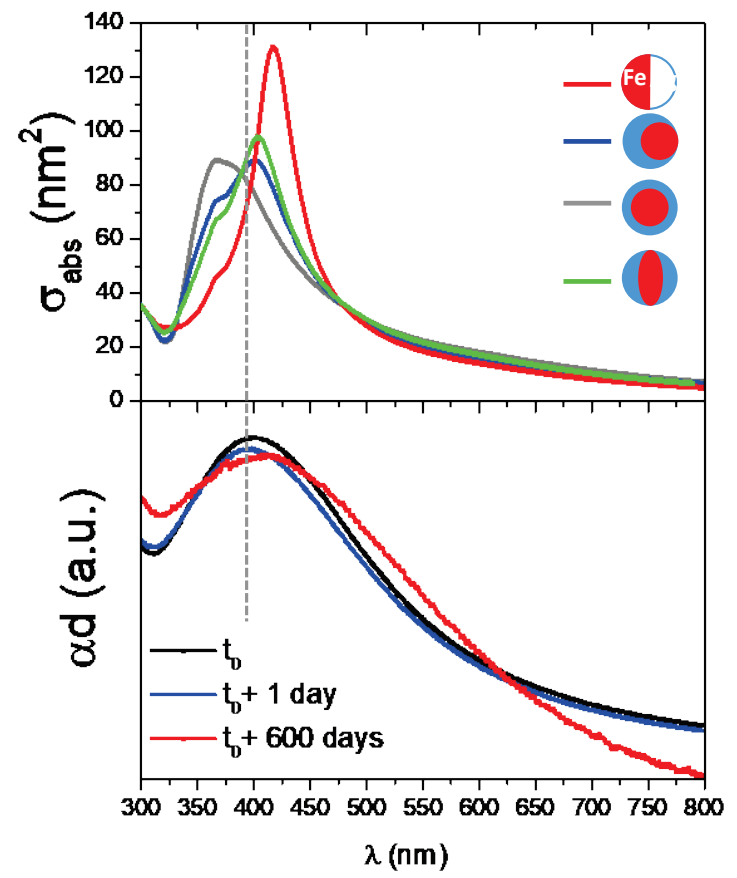

Figure 12. Optical absorption spectra of $\mathrm{Ag}_{0.5} \mathrm{Fe}_{0.5} \mathrm{NPs}$ embedded in alumina $\left(\varepsilon_{m}=2.17\right)$ with the substrate kept at $400{ }^{\circ} \mathrm{C}$ during co-deposition. Upper panel: theoretical absorption crosssections for different NP configurations as Janus (red line), off-centered spherical core-shell Fe@Ag (blue line), spherical core-shell Fe@Ag (gray line), and core-shell Fe@Ag with an oblate core similar to the configuration obtained from Monte Carlo simulations (green line). Lower panel: experimental absorption spectra of as-prepared $\mathrm{Ag}_{\mathrm{x}} \mathrm{Fe}_{1-\mathrm{x}} \mathrm{NPs}$ embedded in alumina just after air exposure at time denoted $t_{o}$ (black line), at time $t_{o}+1$ day after air exposure (blue curve) and at time $t_{o}+600$ days after air exposure (red line).

\section{Conclusions}

In this work the optical and structural properties of silver-iron NPs were investigated at two compositions ( $50 \%$ and $80 \%$ in silver). Parallel tempering Monte Carlo simulations at the atomistic 
level predict that, at room temperature, such systems should preferentially adopt Fe@Ag coreshell crystal structures when isolated. From the experimental point of view, the structure of the native NPs could not be determined because of rapid iron oxidation. Nevertheless, electron microscopy characterizations have shown that the system forms, after iron oxidation, a crystallized silver core surrounded by a less clearly defined iron oxide shell crystallizing under the electron beam into magnetite. Moreover, the development of an environmental optical spectroscopy setup based on the SMS technique allowed the oxidation and reduction of the NPs to be both monitored through the LSPR modifications they induce. Such a setup should enable the monitoring of individual NPs through in operando conditions. Finally, TEM observations and optical characterizations combined with optical and Monte Carlo simulations concur to show that these metals are initially segregated with a silver-enriched surface and that oxidation induces some iron migration towards the surface. After iron reduction, which is not always complete, the system may return to its initial configuration, but optical spectroscopy alone cannot provide a conclusive evidence.

Environmental TEM measurements under controlled atmosphere as already performed on indiumsilver $\mathrm{NPs}^{30}$ are needed to proceed further. Moreover, other characterization techniques like anomal x-ray diffraction ${ }^{73}$ or low energy ion spectroscopy ${ }^{71}$ should also be valuable, especially if performed on NPs protected from oxidation.

\section{ASSOCIATED CONTENT}

Supporting Information 
1. View of the entire environmental setup. 2. Calibration procedure. Theoretical evolution of the LSPR peak maxima for different oxidation scenarios; experimental evolution of the LSPR peak maxima along oxidation/reduction cycles.

\section{AUTHOR INFORMATION}

The authors declare no competing financial interests.

\section{ACKNOWLEDGMENT}

Financial support from GDR 3182 Nanoalliages and European COST Action MP1302 Nanospectroscopy is gratefully acknowledged. We also thank the regional computing center CALMIP for providing generous computational resources (project p1141). The Authors also thank the Centre Lyonnais de Microscopie Electronique (CLYM) for access to the FEI Titan ETEM and N. Blanchard and M. Aouine for technical support. The PhD thesis of J. Ramade was funded by ARC Energie (Academic Research Community), Rhône-Alpes regional council. The samples were

elaborated at the PLYRA facility with the technical support of C. Albin, O. Boisron, C. Clavier and A. Mosset. The initial structure for the MC simulations were transposed from earlier work on Fe-Au NPs and were generated by Dr. Magali Benoit (CEMES, Toulouse, France), whom we gratefully acknowledge.

\section{REFERENCES}


1. Alloyeau, D.; Mottet, C.; Ricolleau, C., Nanoalloys. Springer London: London, 2012.

2. Baletto, F.; Ferrando, R., Structural Properties of Nanoclusters: Energetic,

Thermodynamic, and Kinetic Effects. Rev. Mod. Phys. 2005, 77 (1), 371-423.

3. Nanoalloys: From Fundamentals to Emergent Applications; Calvo, F., Ed. Elsevier: Amsterdam, 2013; p 433.

4. $\quad$ Ferrando, R.; Jellinek, J.; Johnston, R. L., Nanoalloys : From Theory to Applications of Alloy Clusters and Nanoparticles. Chemical Reviews 2008, 108 (3), 845-910.

5. Barcaro, G.; Sementa, L.; Fortunelli, A.; Stener, M., Optical Properties of Nanoalloys. Physical Chemistry Chemical Physics 2015, 17 (42), 27952-27967.

6. Cottancin, E.; Pellarin, M., Optical Probes of The Chemical Structure in Metallic Nanoalloys. In Nanoalloys: From Fundamentals to Emergent Applications, Calvo, F., Ed. Elsevier: 2013; pp 203-245.

7. Cottancin, E.; Fatti, N. D.; Halté, V., Optical, Structural and Magneto-Optical Properties of Metal Clusters and Nanoparticles. In Nanoalloys, Alloyeau, D.; Mottet, C.; Ricolleau, C., Eds. Springer London: 2012; pp 331-368.

8. Cortie, M. B.; McDonagh, A. M., Synthesis and Optical Properties of Hybrid and Alloy Plasmonic Nanoparticles. Chemical Reviews 2011, 111 (6), 3713-3735.

9. Grillet, N.; Manchon, D.; Cottancin, E.; Bertorelle, F.; Bonnet, C.; Broyer, M.; Lermé, J.; Pellarin, M., Photo-Oxidation of Individual Silver Nanoparticles: A Real-Time Tracking of Optical and Morphological Changes. J.Phys. Chem. C 2013, 117 (5), 2274-2782.

10. Cottancin, E.; Langlois, C.; Lermé, J.; Broyer, M.; Lebeault, M.-A.; Pellarin, M., Plasmon spectroscopy of small indium-silver clusters: monitoring the indium shell oxidation. Physical Chemistry Chemical Physics 2014, 16, 5763-5773.

11. Ramade, J.; Troc, N.; Boisron, O.; Pellarin, M.; Lebeault, M. A.; Cottancin, E.; Oiko, V. T. A.; Gomes, R. C.; Rodrigues, V.; Hillenkamp, M., Nano-fried-eggs: Structural, optical, and magnetic characterization of physically prepared iron-silver nanoparticles. Nano Res. 2018, 11 (11), 6074-6085.

12. Demirdjian, B.; Bedu, F.; Ranguis, A.; Ozerov, I.; Karapetyan, A.; Henry, C. R., Indirect Nanoplasmonic Sensing to Probe with a High Sensitivity the Interaction of Water Vapor with Soot Aerosols. J Phys Chem Lett 2015, 6 (20), 4148-4152.

13. Haldar, K. K.; Kundu, S.; Patra, A., Core-Size-Dependent Catalytic Properties of Bimetallic Au/Ag Core-Shell Nanoparticles. ACS Appl. Mater. Interfaces 2014, 6 (24), 2194621953.

14. Tabib Zadeh Adibi, P.; Pingel, T.; Olsson, E.; Grönbeck, H.; Langhammer, C., Plasmonic Nanospectroscopy of Platinum Catalyst Nanoparticle Sintering in a Mesoporous Alumina Support. ACS Nano 2016, 10 (5), 5063-5069.

15. Larsson, E. M.; Langhammer, C.; Zorić, I.; Kasemo, B., Nanoplasmonic Probes of Catalytic Reactions. Science 2009, 326 (5956), 1091-1094.

16. Pellarin, M.; Broyer, M.; Lermé, J.; Lebeault, M.-A.; Ramade, J.; Cottancin, E., Plasmon Resonances Tailored by Fano Profiles in Silver-Based Core-Shell Nanoparticles. Physical Chemistry Chemical Physics 2016, 18, 4121-4133.

17. Armelles, G.; Dmitriev, A., Focus on magnetoplasmonics. New Journal of Physics 2014, $16,045012$.

18. Wang, L.; Clavero, C.; Huba, Z.; Carroll, K. J.; Carpenter, E. E.; Gu, D.; Lukaszew, R. A., Plasmonics and Enhanced Magneto-Optics in Core-Shell $\mathrm{Co}-\mathrm{Ag}$ Nanoparticles. Nano Letters 2011, 11 (3), 1237-1240. 
19. Zaleska-Medynska, A.; Marchelek, M.; Diak, M.; Grabowska, E., Noble metal-based bimetallic nanoparticles: the effect of the structure on the optical, catalytic and photocatalytic properties. Advances in Colloid and Interface Science 2016, 229, 80-107.

20. Grzelak, J.; Krajewska, A.; Krajnik, B.; Jamiola, D.; Choma, J.; Jankiewicz, B.; Piątkowski, D.; Nyga, P.; Mackowski, S., Hybrid silica-gold core-shell nanoparticles for fluorescence enhancement. Nanospectroscopy 2016, 2 (1), 1-6.

21. Wadell, C.; Langhammer, C., Drift-corrected nanoplasmonic hydrogen sensing by polarization. Nanoscale 2015, 7 (25), 10963-10969.

22. Nasir, M. E.; Dickson, W.; Wurtz, G. A.; Wardley, W. P.; Zayats, A. V., Hydrogen Detected by the Naked Eye: Optical Hydrogen Gas Sensors Based on Core/Shell Plasmonic Nanorod Metamaterials. Advanced Materials 2014, 26 (21), 3532-3537.

23. Dallaire, A.-M.; Rioux, D.; Rachkov, A.; Patskovsky, S.; Meunier, M., Laser-Generated $\mathrm{Au}-\mathrm{Ag}$ Nanoparticles For Plasmonic Nucleic Acid Sensing. The Journal of Physical Chemistry C 2012, 116 (20), 11370-11377.

24. Qiu, G.; PangNg, S.; Wu, C.-M. L., Bimetallic Au-Ag alloy nanoislands for highly sensitive localized surface plasmon resonance biosensing. Sensors and Actuators B: Chemical 2018, 265, 459-467.

25. Giorgio, S.; Joao, S. S.; Nitsche, S.; Chaudanson, D.; Sitja, G.; Henry, C. R., Environmental electron microscopy (ETEM) for catalysts with a closed E-cell with carbon windows. Ultramicroscopy 2006, 106 (6), 503-507.

26. Gai, P. L.; Boyes, E. D.; Helveg, S.; Hansen, P. L.; Giorgio, S.; Henry, C. R., Atomicresolution environmental transmission electron microscopy for probing gas-solid reactions in heterogeneous catalysis. MRS Bulletin 2007, 32 (12), 1044-1050.

27. Tao, F.; Salmeron, M., In Situ Studies of Chemistry and Structure of Materials in Reactive Environments. Science 2011, 331 (6014), 171-174.

28. Crozier, P. A.; Hansen, T. W., In situ and operando transmission electron microscopy of catalytic materials. MRS Bulletin 2015, 40 (01), 38-45.

29. Controlled atmosphere transmission electron microscopy: principles and practice; Hansen, T. W.; Wagner, J. B., Eds; Springer: Cham Heidelberg New York, 2016; p 229.

30. Ramade, J.; Langlois, C.; Pellarin, M.; Piccolo, L.; Lebeault, M. A.; Epicier, T.; Aouine, M.; Cottancin, E., Tracking the Restructuring of Oxidized Silver-Indium Nanoparticles Under a Reducing Atmosphere by Environmental HRTEM. Nanoscale 2017, 9 (36), 13563-13574.

31. Scaramuzza, S.; Badocco, D.; Pastore, P.; Coral, D. F.; Fernandez van Raap, M. B.; Amendola, V., Magnetically Assembled SERS Substrates Composed of Iron-Silver Nanoparticles Obtained by Laser Ablation in Liquid. ChemPhysChem 2017, 18 (9), 1026-1034.

32. Kharisov, B. I.; Kharissova, O. V.; Rasika Dias, H. V.; Ortiz Méndez, U.; de la Fuente, I. G.; Peña, Y.; Vázquez Dimas, A., Iron-based Nanomaterials in the Catalysis. In Advanced Catalytic Materials - Photocatalysis and Other Current Trends, Norena, L. E.; Wang, J.-A., Eds. InTech: 2016.

33. Van der Laan, G. P.; Beenackers, A., Kinetics and selectivity of the Fischer-Tropsch synthesis: A literature review. Catal. Rev.-Sci. Eng. 1999, 41 (3-4), 255-318.

34. Sun, S. H.; Murray, C. B.; Weller, D.; Folks, L.; Moser, A., Monodisperse FePt nanoparticles and ferromagnetic FePt nanocrystal superlattices. Science 2000, 287 (5460), 19891992. 
35. Lee, Y. P.; Kudryavtsev, Y. V.; Nemoshkalenko, V. V.; Gontarz, R.; Rhee, J. Y., Magneto-optical and optical properties of Fe-rich Au-Fe alloy films near the fcc-bcc structural transformation region. Physical Review B 2003, 67 (10), 104424.

36. Lyon, J. L.; Fleming, D. A.; Stone, M. B.; Schiffer, P.; Williams, M. E., Synthesis of Fe Oxide Core/Au Shell Nanoparticles by Iterative Hydroxylamine Seeding. Nano Letters 2004, 4 (4), 719-723.

37. Benoit, M.; Langlois, C.; Combe, N.; Tang, H.; Casanove, M.-J., Structural and electronic properties of the $\mathrm{Au}(001) / \mathrm{Fe}(001)$ interface from density functional theory calculations. Physical Review B 2012, 86 (7), 075460.

38. Amendola, V.; Meneghetti, M.; Bakr, O. M.; Riello, P.; Polizzi, S.; Anjum, D. H.; Fiameni, S.; Arosio, P.; Orlando, T.; Fernandez, C. d. J.; Pineider, F.; Sangregorio, C.; Lascialfari, A., Coexistence of plasmonic and magnetic properties in Au89Fe11 nanoalloys. Nanoscale 2013, 5 (12), 5611-5619.

39. Amendola, V.; Scaramuzza, S.; Agnoli, S.; Polizzi, S.; Meneghetti, M., Strong dependence of surface plasmon resonance and surface enhanced Raman scattering on the composition of Au-Fe nanoalloys. Nanoscale 2014, 6 (3), 1423-1433.

40. Baumgardner, W. J.; Yu, Y.; Hovden, R.; Honrao, S.; Hennig, R. G.; Abruña, H. D.; Muller, D.; Hanrath, T., Nanoparticle Metamorphosis: An in Situ High-Temperature Transmission Electron Microscopy Study of The Structural Evolution of Heterogeneous $\mathrm{Au}: \mathrm{Fe}_{2} \mathrm{O}_{3}$ Nanoparticles. Acs Nano 2014, 8 (5), 5315-5322.

41. Papaefthimiou, V.; Tournus, F.; Hillion, A.; Khadra, G.; Teschner, D.; Knop-Gericke, A.; Dupuis, V.; Zafeiratos, S., Mixing Patterns and Redox Properties of Iron-Based Alloy Nanoparticles under Oxidation and Reduction Conditions. Chemistry of Materials 2014, 26 (4), 1553-1560.

42. $\quad$ Langlois, C.; Benzo, P.; Arenal, R.; Benoit, M.; Nicolai, J.; Combe, N.; Ponchet, A.; Casanove, M. J., Fully Crystalline Faceted Fe-Au Core-Shell Nanoparticles. Nano Letters 2015. 43. Lu, L.; Zhang, W.; Wang, D.; Xu, X.; Miao, J.; Jiang, Y., Fe@Ag core-shell nanoparticles with both sensitive plasmonic properties and tunable magnetism. Mater. Lett. 2010, 64 (15), 1732-1734.

44. Benelmekki, M.; Bohra, M.; Kim, J.-H.; Diaz, R. E.; Vernieres, J.; Grammatikopoulos, P.; Sowwan, M., A facile single-step synthesis of ternary multicore magneto-plasmonic nanoparticles. Nanoscale 2014, 6 (7), 3532-3535.

45. Amendola, V.; Scaramuzza, S.; Agnoli, S.; Granozzi, G.; Meneghetti, M.; Campo, G.; Bonanni, V.; Pineider, F.; Sangregorio, C.; Ghigna, P.; Polizzi, S.; Riello, P.; Fiameni, S.; Nodari, L., Laser generation of iron-doped silver nanotruffles with magnetic and plasmonic properties. Nano Res. 2015, 8 (12), 4007-4023.

46. Luo, S.; Yang, S.; Sun, C.; Gu, J.-D., Improved debromination of polybrominated diphenyl ethers by bimetallic iron-silver nanoparticles coupled with microwave energy. Sci. Total Environ. 2012, 429, 300-308.

47. Mahmoudi, M.; Serpooshan, V., Silver-Coated Engineered Magnetic Nanoparticles Are Promising for the Success in the Fight against Antibacterial Resistance Threat. ACS Nano 2012, 6 (3), 2656-2664.

48. Marková, Z.; Šišková, K. n. M.; Filip, J.; Čuda, J.; Kolář, M.; Šafářová, K.; Medř́k, I.; Zbořil, R., Air Stable Magnetic Bimetallic Fe-Ag Nanoparticles for Advanced Antimicrobial Treatment and Phosphorus Removal. Environ. Sci. Technol. 2013, 47 (10), 5285-5293. 
49. Lin, A. Y.; Young, J. K.; Nixon, A. V.; Drezek, R. A., Encapsulated Fe3O4/Ag Complexed Cores in Hollow Gold Nanoshells for Enhanced Theranostic Magnetic Resonance Imaging and Photothermal Therapy. Small 2014, 10 (16), 3246-3251.

50. Moscoso-Londoño, O.; Muraca, D.; Tancredi, P.; Cosio-Castañeda, C.; Pirota, K. R.; Socolovsky, L. M., Physicochemical Studies of Complex Silver-Magnetite Nanoheterodimers with Controlled Morphology. The Journal of Physical Chemistry C 2014, 118 (24), 1316813176.

51. Swartzendruber, L. J., The Ag-Fe (Silver-Iron) system. Bulletin of Alloy Phase Diagrams 1984, 5 (6), 560-564.

52. Yaws, C. L., Chemical properties handbook: physical, thermodynamic, environmental, transport, safety, and health related properties for organic and inorganic chemicals. Mc Graw Hill: New-York, 1999.

53. Carroll, K. J.; Hudgins, D. M.; Spurgeon, S.; Kemner, K. M.; Mishra, B.; Boyanov, M. I.; Brown, L. W.; Taheri, M. L.; Carpenter, E. E., One-Pot Aqueous Synthesis of Fe and Ag Core/Shell Nanoparticles. Chemistry of Materials 2010, 22 (23), 6291-6296.

54. Arbouet, A.; Christofilos, D.; Del Fatti, N.; Vallee, F.; Huntzinger, J. R.; Arnaud, L.; Billaud, P.; Broyer, M., Direct measurement of the single-metal-cluster optical absorption. Physical Review Letters 2004, 93 (12), 127401.

55. Billaud, P.; Marhaba, S.; Grillet, N.; Cottancin, E.; Bonnet, C.; Lermé, J.; Vialle, J.-L.; Broyer, M.; Pellarin, M., Absolute optical extinction measurements of single nano-objects by spatial modulation spectroscopy using a white lamp. Review of Scientific Instruments 2010, 81 (4), 043101.

56. Zhou, X. W.; Johnson, R. A.; Wadley, H. N. G., Misfit-energy-increasing dislocations in vapor-deposited CoFe/NiFe multilayers. Physical Review B 2004, 69 (14), 144113.

57. Calvo, F.; Cottancin, E.; Broyer, M., Segregation, core alloying, and shape transitions in bimetallic nanoclusters: Monte Carlo simulations. Phys. Rev. B 2008, 77, 121406(R).

58. Perez, A.; Melinon, P.; Dupuis, V.; Bardotti, L.; Masenelli, B.; Tournus, F.; Prevel, B.; Tuaillon-Combes, J.; Bernstein, E.; Tamion, A.; Blanc, N.; Tainoff, D.; Boisron, O.; Guiraud, G.; Broyer, M.; Pellarin, M.; Fatti, N. D.; Vallee, F.; Cottancin, E.; Lermé, J.; Vialle, J.-L.; Bonnet, C.; Maioli, P.; Crut, A.; Clavier, C.; Rousset, J. L.; Morfin, F., Functional Nanostructures From Clusters. Internantional Journal of Nanotechnology 2010, 7, 523-574. 59. Gaudry, M.; Cottancin, E.; Pellarin, M.; Lermé, J.; Arnaud, L.; Huntzinger, J.; Vialle, J.; Broyer, M.; Rousset, J.; Treilleux, M.; Mélinon, P., Size and composition dependence in the optical properties of mixed (transition metal/noble metal) embedded clusters. Physical Review B 2003, 67 (15), 155409.

60. Alayan, R.; Arnaud, L.; Bourgey, A.; Broyer, M.; Cottancin, E.; Huntzinger, J. R.; Lermé, J.; Vialle, J. L.; Pellarin, M.; Guiraud, G., Application of a static quadrupole deviator to the deposition of size-selected cluster ions from a laser vaporization source. Review of Scientific Instruments 2004, 75 (7), 2461-2470.

61. Pecharroman, C.; Gonzalezcarreno, T.; Iglesias, J., The Infrared Dielectric-Properties of Maghemite, Gamma-Fe2o3, from Reflectance Measurement on Pressed Powders. Phys Chem Minerals 1995, 22 (1), 21-29.

62. Bosi, F.; Halenius, U.; Skogby, H., Crystal chemistry of the magnetite-ulvospinel series. Am. Miner. 2009, 94 (1), 181-189.

63. Lemire, R. J., Chemical thermodynamics of iron, part 1 In Chemical Thermodynamics, Perrone, J., Ed. NEA No. 6355 C OECD: Issy-les-Moulineaux (France), 2013; Vol. 13a. 
64. Meng, S.; Wu, J.; Zhao, L.; Zheng, H.; Jia, S.; Hu, S.; Meng, W.; Pu, S.; Zhao, D.; Wang, J., Atomistic Insight into the Redox Reactions in Fe/Oxide Core-Shell Nanoparticles. Chemistry of Materials 2018, 30 (20), 7306-7312.

65. Palik, E. D., Handbook of optical constants of solids. Academic Press: New York, 19851991; Vols. I and II.

66. Johnson, P.; Christy, R., Optical-Constants of Transition-Metals - Ti, V, Cr, Mn, Fe, Co, Ni, and Pd. Physical Review B 1974, 9 (12), 5056-5070.

67. Triaud, A., www.astro.uni-jena.de. http://www.astro.uni-

jena.de/Laboratory/OCDB/mgfeoxides.html\#C.

68. Cottancin, E.; Broyer, M.; Lermé, J.; Pellarin, M., In Handbook of Nanophysics:

Nanoelectronics and Nanophotonics. Sattler, D. K.; Taylor \& Francis CRC Press: Boca Raton, 2011, Vol.6, 24-1 - 24-25.

69. Campos, A.; Troc, N.; Cottancin, E.; Pellarin, M.; Weissker, H.-C.; Lermé, J.; Kociak, M.; Hillenkamp, M., Plasmonic quantum size effects in silver nanoparticles are dominated by interfaces and local environments. Nat Phys 2018.

70. Granqvist, C.; Hunderi, O., Optical absorption of ultrafine metal spheres with dielectric cores. Zeitschrift für Physik B: Condens. Matter 1978, 30, 47-51.

71. Cottancin, E.; Gaudry, M.; Pellarin, M.; Lermé, J.; Arnaud, L.; Huntzinger, J. R.; Vialle, J. L.; Treilleux, M.; Mélinon, P.; Rousset, J. L.; Broyer, M., Optical properties of mixed clusters: comparative study of Ni/Ag and Pt/Ag clusters. The European Physical Journal D - Atomic, Molecular, Optical and Plasma Physics 2003, 24 (1), 111-114.

72. Celep, G.; Cottancin, E.; Lermé, J.; Pellarin, M.; Arnaud, L.; Huntzinger, J. R.; Viallle, J. L.; Broyer, M.; Palpant, B.; Boisron, O.; Mélinon, P., Optical properties of copper clusters embedded in alumina: an experimental and theoretical study of size dependence. Physical Review B 2004, 70, 165409.

73. Andreazza, P.; Pierron-Bohnes, V.; Tournus, F.; Andreazza-Vignolle, C.; Dupuis, V., Structure and order in cobalt/platinum-type nanoalloys: from thin films to supported clusters. Surface Science Reports 2015, 70 (2), 188-258. 


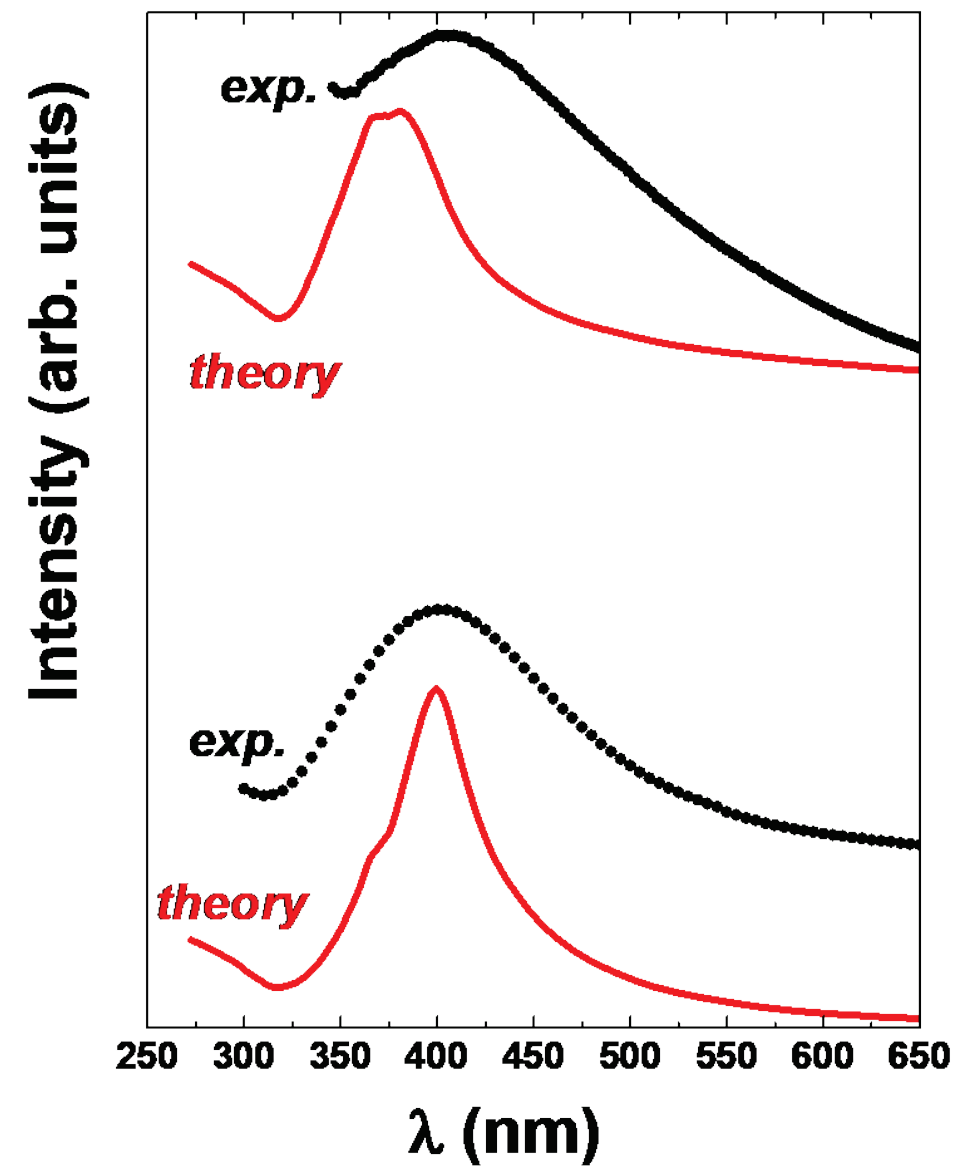

$\mathrm{Ag}_{0.5} \mathrm{Fe}_{0.5}$

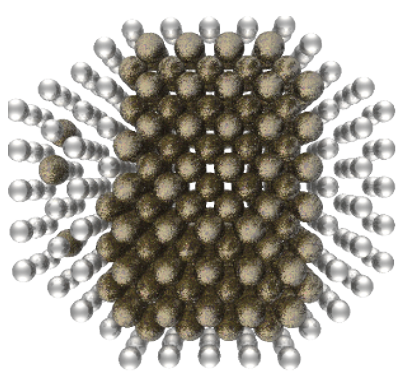

$\mathrm{Ag}_{0.8} \mathrm{Fe}_{0.2}$

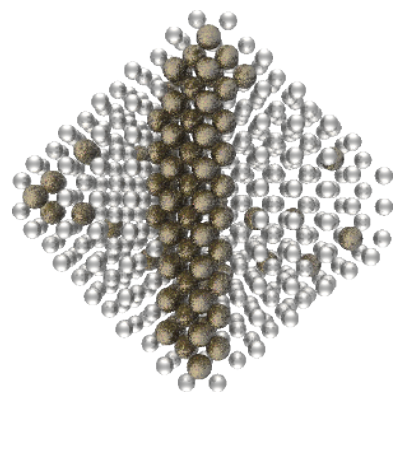

TOC image 